\title{
Preservation of blood glucose homeostasis in slow-senescing somatotrophism-deficient mice subjected to intermittent fasting begun at middle or old age
}

\author{
Oge Arum • Jamal K. Saleh • Ravneet K. Boparai • \\ John J. Kopchick • Romesh K. Khardori • \\ Andrzej Bartke
}

Received: 3 December 2013 / Accepted: 26 March 2014 / Published online: 1 May 2014

(C) American Aging Association 2014

\begin{abstract}
Poor blood glucose homeostatic regulation is common, consequential, and costly for older and elderly populations, resulting in pleiotrophically adverse clinical outcomes. Somatotrophic signaling deficiency and dietary restriction have each been shown to delay the rate of senescence, resulting in salubrious phenotypes such as increased survivorship. Using two growth hormone $(\mathrm{GH})$ signaling-related, slow-aging mouse mutants we tested, via longitudinal analyses, whether genetic perturbations that increase survivorship also improve blood glucose homeostatic regulation in senescing mammals. Furthermore, we institute a dietary
\end{abstract}

Electronic supplementary material The online version of this article (doi:10.1007/s11357-014-9651-2) contains supplementary material, which is available to authorized users.

O. Arum · J. K. Saleh · R. K. Boparai · A. Bartke

Department of Internal Medicine, Southern Illinois University

School of Medicine,

Springfield, IL 62794, USA

\section{J. J. Kopchick}

Edison Biotechnology Institute and Department of

Biomedical Sciences, Heritage College of Osteopathic

Medicine, Ohio University,

Athens, OH 45701, USA

R. K. Khardori

Department of Internal Medicine, Division of Endocrinology and Metabolism, Eastern Virginia Medical School,

700 West Olney Road, Norfolk, VA 23507, USA

O. Arum (ه)

631 N. 6th Street, 2B, Springfield, IL 62702, USA

e-mail: oge.arum@gmail.com restriction paradigm that also decelerates aging, an intermittent fasting (IF) feeding schedule, as either a shortterm or a sustained intervention beginning at either middle or old age, and assess its effects on blood glucose control. We find that either of the two genetic alterations in GH signaling ameliorates fasting hyperglycemia; additionally, both longevity-inducing somatotrophic mutations improve insulin sensitivity into old age. Strikingly, we observe major and broad improvements in blood glucose homeostatic control by IF: IF improves ad libitum-fed hyperglycemia, glucose tolerance, and insulin sensitivity, and reduces hepatic gluconeogenesis, in aging mutant and normal mice. These results on correction of aging-resultant blood glucose dysregulation have potentially important clinical and public health implications for our ever-graying global population, and are consistent with the Longevity Dividend concept.

Keywords Healthspan · Neuroendocrinology · Growth hormone $\cdot$ Intermittent fasting $\cdot$ Longevity $\cdot$ Mice

\section{Introduction}

Neuroendocrinological frailty represents the facet of overall, multi-system, aging-resultant frailty that involves the dysregulation in neuroendocrine system efficacy including, yet not limited to, ineffective blood glucose homeostasis regulation. As such, it is a major clinical concern in geriatric medicine (Smith et al. 2002; Bourdel-Marchasson and Berrut 2005; Topinková 2008; Chen et al. 2010; Halter 2012). Fasting and basal 
hyperglycemia increase with age (Greene 1986; Dominguez et al. 2010) as do glycemic responses to a challenge with a bolus of glucose (Viljoen and Sinclair 2011; Gong and Muzumdar 2012). This aging-resultant decline in insulin action is even more troubling considering the increased prevalence of metabolic derangements, including the development of metabolic syndrome or type 2 diabetes mellitus (T2DM), occurring across all age and socioeconomic classes in developed countries (Centers for Disease Control and Prevention 2011, 2012). These glucose homeostasis-related conditions manifest clinically as microvascular pathologies of the nervous, renal, and vision systems; increased risk of adverse macrovascular cardiovascular outcomes (such as myocardial infarcts, strokes, or cardiomyopathy), increased immunological inefficacy, and heightened mortality (Valeri et al. 2004; Centers for Disease Control and Prevention 2011, 2012). Therefore, the development of modalities of treatment for these disabilities and disorders is of paramount public health importance.

Growth hormone $(\mathrm{GH})$ signaling-deficient mice constitute the preeminent murine genetic model of delayed and/or decelerated senescence (Berryman et al. 2008). These mice with deficiencies in hormonal transduction of somatotrophic signaling, and with the consequent dwarfism, are not merely longlived relative to their littermate controls (Bartke and Brown-Borg 2004), but are slow-aging; as substantiated by the amelioration of aging-associated phenotypes such as neoplastic disease (Ikeno et al. 2003, 2009), cognitive decline (Kinney et al. 2001a, b; Kinney-Forshee et al. 2004), collagen crosslinking and markers of immunosenescence (Flurkey et al. 2001), and neuromusculoskeletal frailty (Arum et al. 2013, 2014). The first of this class to be identified as long-lived (Brown-Borg et al. 1996) is the hypopituitary Ames Dwarf mouse (Schaible and Gowen 1961). Identified as a spontaneously emerging mutant, mice homozygous for the $d f$ allele at the Prophet of Pit1 (Prop1) locus (Sornson et al. 1996) have primary deficiencies in development of the anterior pituitary; this leads to markedly decreased production of GH and prolactin (Bartke 1965; Slabaugh et al. 1981), and thyrotrophin (Bartke 1965) from the anterior pituitary (Gage et al. 1996). The subsequent deficiency in hepatic insulin-like growth factor 1 (IGF-1)-mediated and
IGF-1-independent growth leads to a mouse approximately half of the weight of its littermate control.

The second, and most extensively characterized, member of this group is the growth hormone receptor/ binding protein gene-disrupted ("knockout") (GHR-KO) mouse. The result of targeted insertion of a neomycin cassette replacing the 3 '-end of the fourth exon and the 5 '-end of intron $4 / 5$ of the genomic sequence of the growth hormone receptor/binding protein $(G h r / b p)$ gene, this mouse model of human Laron Syndrome is resistant to GH (Zhou et al. 1997). Thus, it has futilely increased levels of GH, yet decreased levels of circulating IGF-1 due to the ineffectual $\mathrm{GH}$ receptors on the hepatocytes that produce and secrete GH-dependent IGF-1; and it is approximately $2 / 3$ the weight and $3 / 4$ the length of its littermate control. One cluster of consequences of this dwarfism is lighter pancreata, pancreatic islets one-third the size of those from littermate controls (albeit with normal islet distribution within the pancreas), and a 4.5 -fold reduction in $\beta$-cell mass (Liu et al. 2004). The ensuing hypoinsulinemia, together with the absence of GH signals, results in increased whole-body insulin sensitivity in all members of this GH signaling-deficient class examined to date (Bartke 2008). Results obtained, in part, from investigations into these two stocks established that robust regulation of mammalian senescence can be achieved by single-gene alterations (Bartke 2011; Coschigano et al. 2000, 2003), and that augmented insulin sensitivity is strongly associated with a delayed onset/rate of aging in mice (Bartke 2012) and human beings (Wijsman et al. 2011).

Dietary restriction regimens, "undernutrition without malnutrition" paradigms in which some feature of dietary intake is restricted whilst maintaining sufficient macro- and micro-nutrient intake, have been extensively documented to improve health and increase survivorship for over a century (Moreschi 1909; Rous 1914; McCay et al. 1935; Goto 2006; Roth and Polotsky 2012). In particular, intermittent fasting (IF) is the dietary restriction regimen that repeatedly restricts access to food for a continuous, intervening period (usually every other 24-h period) (Carlson and Hoelzel 1946; Anson et al. 2005; Martin et al. 2006). Notably, calorically equivalent IF has been documented to be more effective than reduced-dailyfeeding caloric restriction (CR) approaches for 
neurobiological protection (Anson et al. 2003; Mattson et al. 2003). Recent clinical investigations have documented the benefits of short-term IF in both obese (Varady et al. 2009; Varady 2011) and normal-weight human subjects (Heilbronn et al. 2005; Varady and Hellerstein 2007; Trepanowski et al. 2011). However, the effect of IF on blood glucose regulatory dynamics in mice has been rarely assessed (Anson et al. 2003; Arum et al. 2009; Lu et al. 2011). Considering the validated adherence and easy modifiability of IF regimens for clinical intervention, studies into the outcomes of IF upon middle-aged or older subjects are very important for addressing the aging-associated declines in blood glucose control in a graying population (Kinsella and Wan 2009).

Four major unresolved issues served as the impetuses for this study: firstly, although insulin sensitivity and glucose intolerance have been documented in young adult Ames Dwarfs and GHRKO mice (Dominici et al. 2002; Liu et al. 2004; reviewed in Bartke 2008), examinations have not been made upon middle-aged, old, or oldest-old mice of these stocks. Taking into account the tendency for insulin resistance to increase progressively with age, and the potential clinical relevance of late-life interventions, these studies are long overdue. Secondly, the impact of GH excess on glucose homeostasis in $\mathrm{GH}$ transgenic mice is, in an age-independent manner, surprisingly discordant with previous presumptions and assertions (Boparai et al. 2010). Thirdly, the effects of short-term, or maintained, IF upon middle-aged (or older) subjects have never been studied. Finally, any potential additive or synergistic effects of the genetic and environmental (dietary) alterations in middle- or old-age have not even been proposed.

Thus, the objectives of the study presented herein are (1) to address the regulation of blood glucose levels in senescing Ames Dwarf and GHR-KO mice, and (2) to study the effects of IF initiated in late life on these animals and their (normal) littermates. We conducted this longitudinal analysis by (1) placing middle-aged GHR-KO females on a 3-month course of IF, and maintaining it until they were old; and (2) instituting a 3month course of IF on old Ames Dwarf males, and sustaining that until they were oldest-old.
These investigations attempt to leverage the existence of these (genetic and environmental) modifications that increase lifespan in order to study whether they extend further into the realm of "healthspan," defined as the period of life during which an organism is functionally able to sustain independent existence and is free from substantial morbidity (Olshansky et al. 2007; Warner and Sierra 2009; Miller 2009; Kenyon 2010).

\section{Results}

Our study involved 16 subgroups, delineated by stock (GHR-KO or Ames Dwarf), phenotype (dwarf or normal-sized), feeding frequency (ad libitum [AL] or intermittently fasted), and age (middle-aged, old, or oldest-old).

Longitudinal effects of IF on body weight, food consumption, and metabolizable energy availability

IF did not significantly affect the body weight (BW) trajectory of either middle-aged female GHR-KO (KO) mice, or their littermate controls (GHR-N [N]) (Fig. 1a). Neither did IF affect the BW change, over time, of the old Ames Dwarf (Prop1 $\left.{ }^{d f / d f}[\mathrm{Df}]\right)$ males, or their littermate controls (Prop $^{d f /+}[\mathrm{N}]$ ) (Fig. 1b). Correspondingly, IF induced compensatory hyperphagia on the days when food was available, as measured by the average daily food consumption (in weight) in both middle-aged KO females $(p<0.0001)$ and their $\mathrm{N}$ littermate controls $(p<0.0001)$ (Fig. 1c), with the same hyperphagic effect being seen for old Df males $(p<0.0001)$ and their $\mathrm{N}$ littermates $(p<0.0001)$ (Fig. 1d). When the proportion of food consumption that could be metabolized into useable energy was considered, IF effected a hyperconsumptive effect on the metabolizable energy (ME) consumption of middle-aged $\mathrm{KO}$ females $(p<0.0001)$ and their $\mathrm{N}$ controls $(p<0.0001)$ (Fig. 1e). The same hyperconsumption of ME, upon IF, was seen for old Df males $(p<0.0001)$ and their $\mathrm{N}$ counterparts $(p<0.0001)$ (Fig. 1f). Similar evidence of the compensatory hyperphagia of intermittently fasted mice has been previously documented (Roe et al. 1995; Wang et al. 2004; Anson et al. 2003; Arum et al. 2009). 
Studies on animal subjects subjected to short-duration (13 weeks) IF AL-fed or fasted glucose tolerance tests in middle-aged GHR-KO or old Ames Df mice

Poor assimilation of post-prandial blood glucose is common with increasing age, and is associated with increased cardiovascular disease risk and total mortality (Crandall et al. 2009); it is also indicative of defective production, storage, release and/or action of insulin (Chang and Halter 2003). We evaluated whether the $G h r / b p$ gene disruption, or 13 weeks of IF, affects incorporation of a $2-\mathrm{g}$ glucose (per kilogram of BW) bolus in middleaged mice. GHR-KO mice exhibit poorer glucose tolerance relative to their normal littermates (Coschigano et al. 1999; Guo et al. 2005), which is consistent with the reductions in both pancreatic mRNA and blood protein content of insulin (Liu et al. 2004), and the decreased glucose-stimulated insulin secretory ability of the $\beta$-cells (Guo et al. 2005) of GHR-KO mice. We found that KO female mutants, which remain innately glucoseintolerant relative to $\mathrm{N}$ controls into middle age ( $p=0.0493$ for AL-fed testing; Fig. 2a), show, when treated with IF, markedly improved clearance of blood glucose during testing for which they were not fasted beforehand ( $p=0.0169$; Fig. 2a), and during that for which they were fasted for approximately $16 \mathrm{~h}$ beforehand ( $p=0.0001$; Fig. $2 b$ ). This beneficial effect of IF on blood glucose handling was also manifested for littermate controls of the middle-aged KO females ( $p=0.0479$ for AL-fed testing, Fig. 2a; $p=0.0243$ for fasted testing, Fig. 2b). What is more, a combinatorial effect of $G h r / b p$ disruption and the IF diet further enhanced blood glucose regulatory dynamics in fasted middleaged GHR-KO females ( $p=0.0003$ for fasted testing; Fig. 2b). As an important note, no dietinduced differences in body weight were present at the time of testing for either AL-fed (Fig. S1) or fasted (Fig. S3) blood glucose tolerance.

We also investigated whether the Propl gene mutation-related hypopituitarism, or 13 weeks of IF, affects assimilation of a 2-g glucose (per $\mathrm{kg}$ $\mathrm{BW}$ ) bolus in old mice. We found that Df male mutant mice, which also maintain their inherent glucose intolerance relative to $\mathrm{N}$ controls into old age (only during fasted testing conditions, $p=0.0181$; Fig. 2d), show, when treated with $I F$, tentatively
Fig. 1 Experimental design sketches and food consumption measurements revealed no effect of intermittent fasting on body weight; probably due, in part, to compensatory hyperphagia. a Experimental design of portion of study conducted on female GHR-KO Stock animals aged 15-19 months at inception, including body weight trajectories and testing windows. b Experimental design of portion of study conducted on male Ames Dwarf Stock animals aged 12-16 months at inception, including body weight trajectories and testing windows. $\mathbf{c}$ Food consumption tracking in female GHR-KO Stock mice on IF depicting that mice (of either phenotype) on IF consumed more food per feeding day than their AL counterparts. d Food consumption tracking in male Ames Dwarf Stock mice on IF depicting that mice (of either phenotype) on IF consumed more food per feeding day than their AL counterparts. e Metabolizable energy consumption-tracking arcs for female GHR-KO (KO) and female littermate control $(\mathrm{N})$ mice on IF detailing that mice on IF consumed more metabolizable energy per feeding day than their AL controls. f Metabolizable energy consumption-tracking arcs for male Ames Dwarf (Df) and male N littermate mice on IF detailing that mice on IF consumed more metabolizable energy per feeding day than their AL controls. All measures of central tendency are arithmetic means, and all depictions of variation (error bars) represent standard deviations $(S D)$

improved clearance of blood glucose during testing for which they were not fasted beforehand $(p=0.0753$; Fig. 2c). Additionally, there was a tentative combined effect of Ames Dwarfism and IF on the glucose intolerance of old Ames Dwarf littermate controls $(p=0.0781$; Fig. 2c). As for during that testing for which they were fasted for approximately $16 \mathrm{~h}$ beforehand, IF improved the incorporation of an exogenous glucose bolus in glucoseintolerant old Ames Dwarf males ( $p=0.0131$; Fig. 2d). Importantly, no diet-related differences in body weight were present for either AL-fed (Fig. S5) or fasted (Fig. S7) blood glucose tolerance testing.

Insulin tolerance tests in middle-aged GHR-KO or old Ames Df mice

Further exacerbating the deterioration of blood glucose homeostasis management during aging is reduced action of insulin upon its signaling cascade proteins, as indicated by glucose transportermediated blood glucose uptake by insulin-actionable cells (Couet et al. 1992). We tested the influence of the $G h r / b p$ gene disruption, or the brief period of IF, upon sensitivity to a 1 United States Pharmacopeia Unit (USPU) of insulin (per kilogram BW) dose. Due to their defects in insulin production, storage, 
a

Female GHR-KO on Intermittent Fasting Body Weight Trajectory

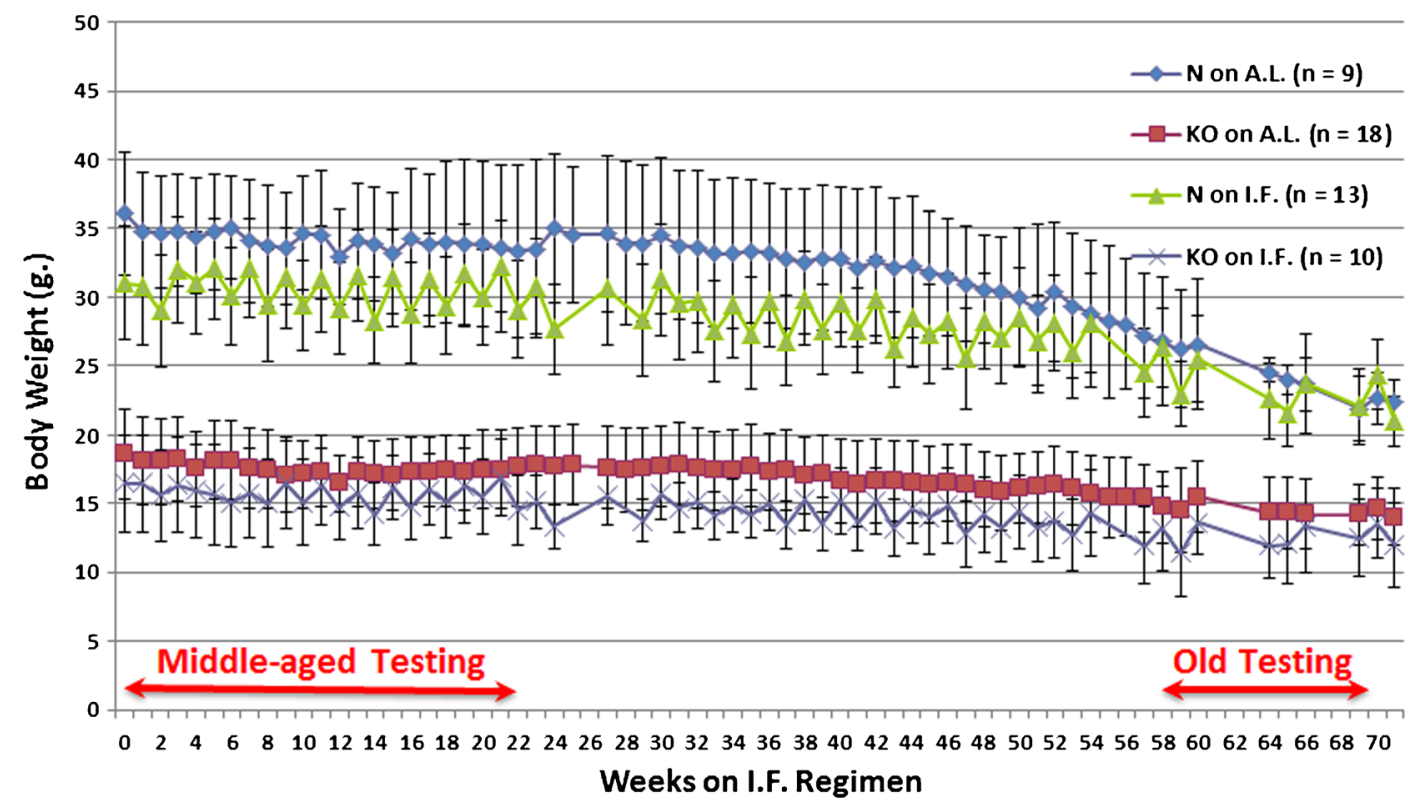

b Male Ames Dwarf on Intermittent Fasting Body Weight Trajectory

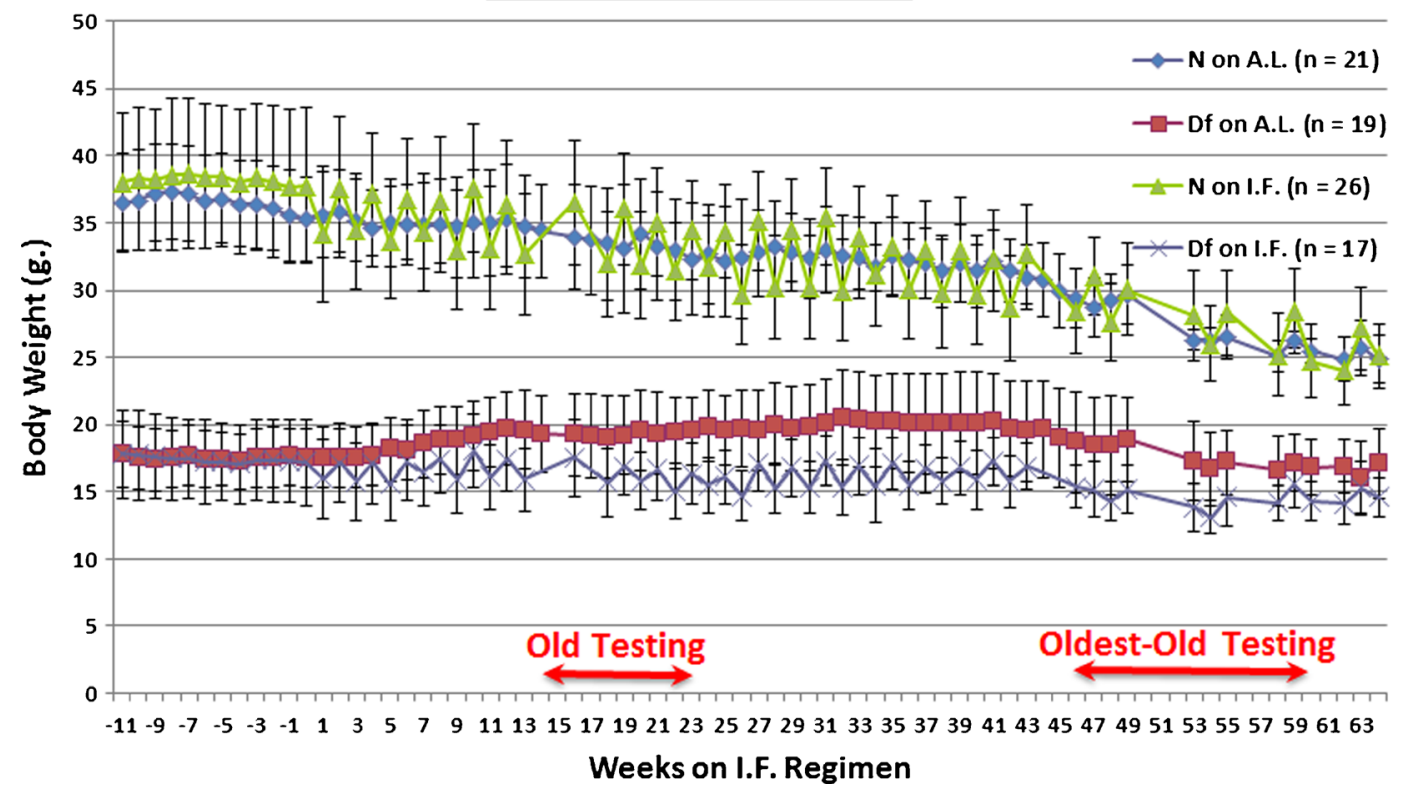

and/or secretion, young adult $\mathrm{KO}$ mice are insulinsensitive relative to their controls (Liu et al. 2004). We tentatively observed that middle-aged KO females maintain this insulin sensitivity $(p=0.2079$; Fig. 2c). Although IF did not improve insulin sensitivity in middle-aged $\mathrm{N}$ females; it did further 
c

Female GHR-KO on Intermittent Fasting

Food Consumption

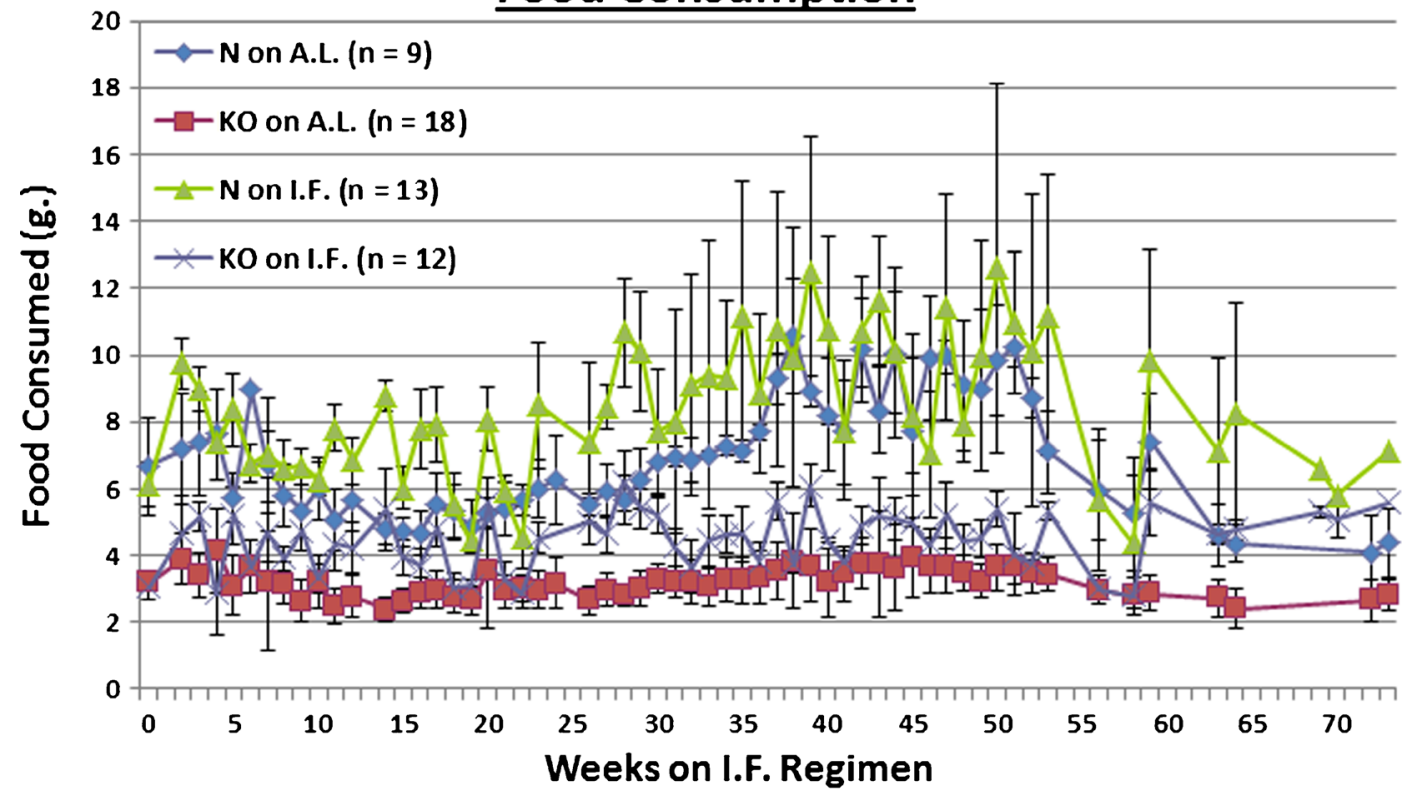

d

Male Ames Dwarf on Intermittent Fasting

Food Consumption

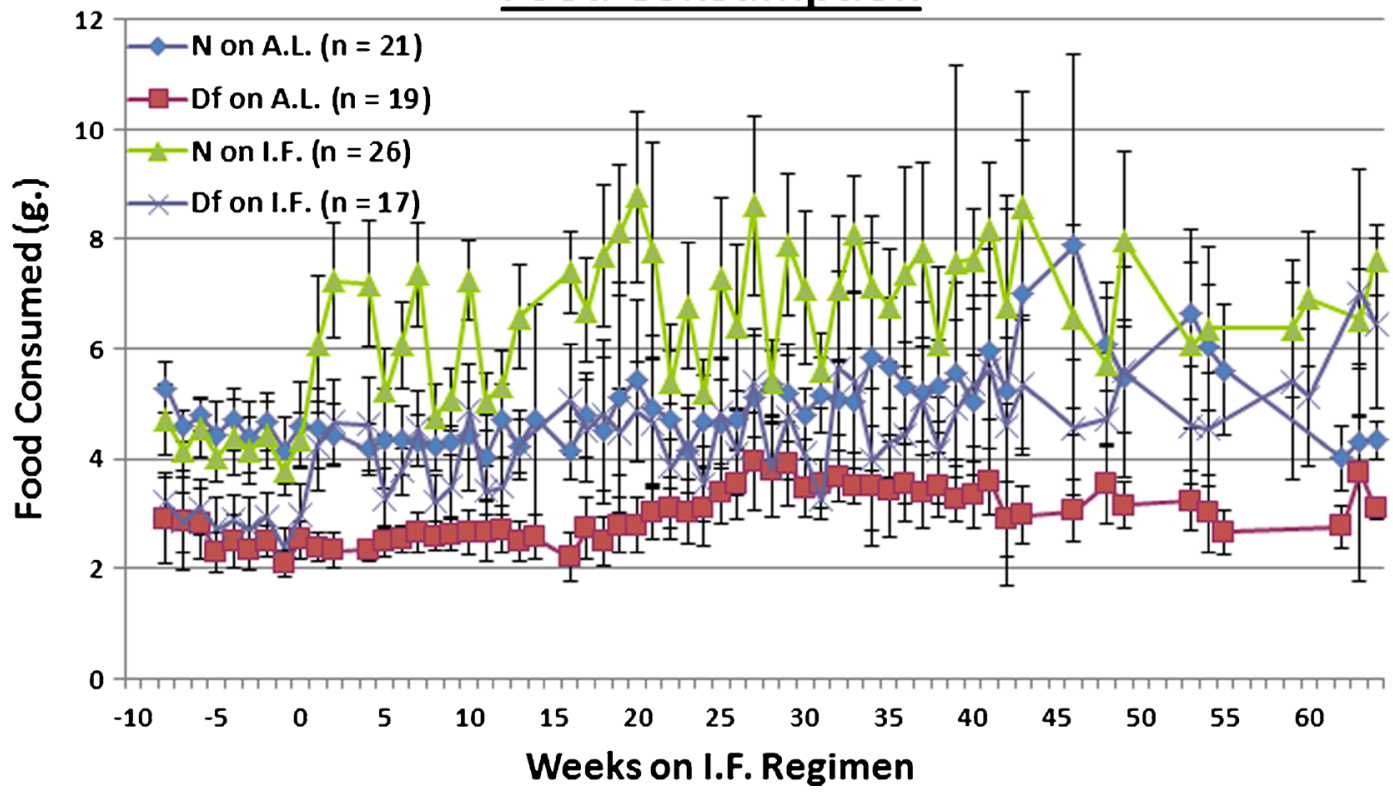

Fig. 1 (continued)

potentiate insulin sensitivity in middle-aged $\mathrm{KO}$ females, relative to middle-aged $\mathrm{N}$ littermates on $\mathrm{AL}$
( $p=0.0538$; Fig. 3a). No diet-induced differences in BW were noted (Fig. S9). 

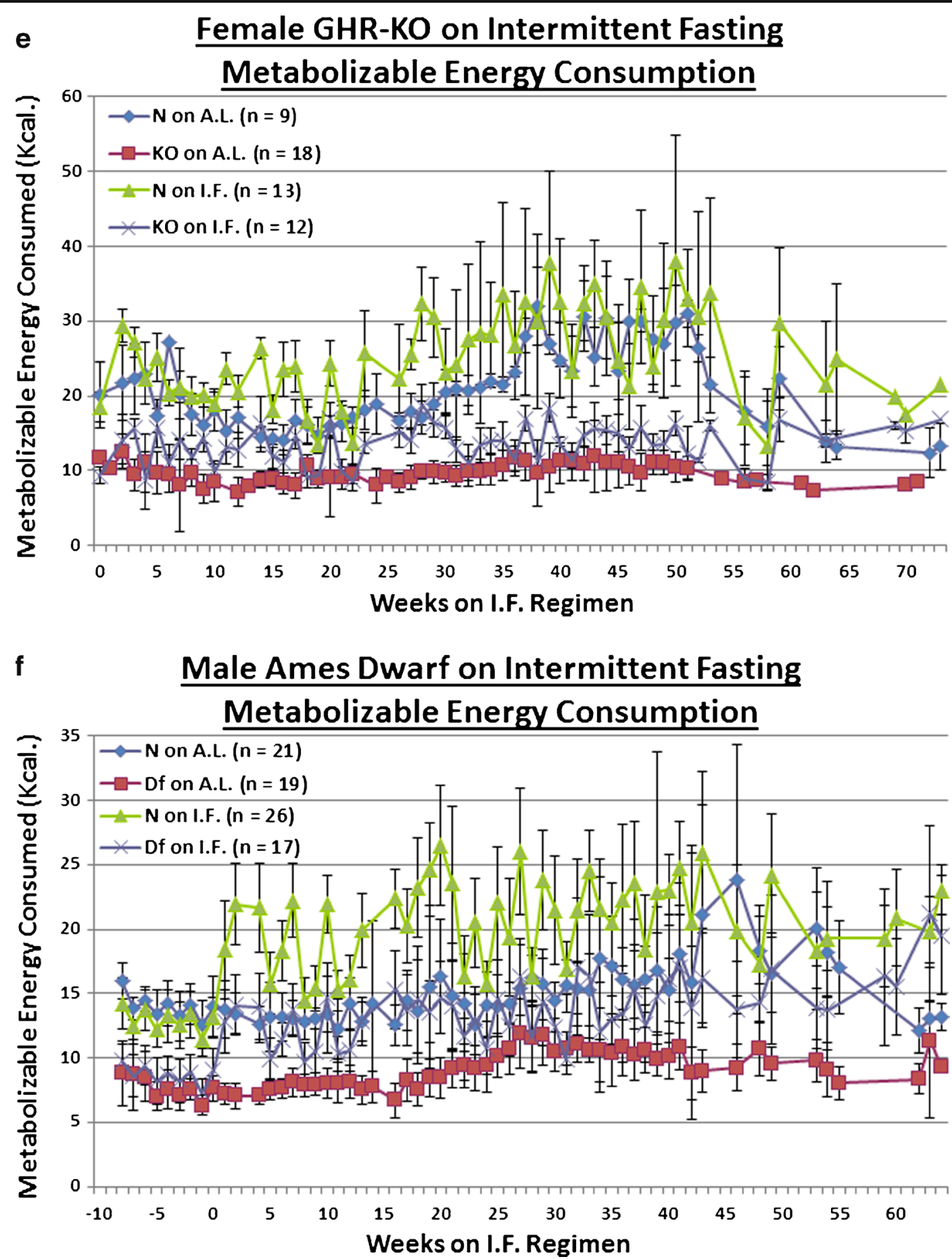

Fig. 1 (continued)

Old Df males were also assessed for insulin sensitivity to 1 USPU of insulin. Ames Dwarfs also develop insulin sensitivity (Borg et al. 1995) and, among the mechanisms involved, their inherent hypoinsulinemia is extremely important (Borg et al. 1995). We observed that Df males maintain their enhanced insulin sensitivity 


\section{a $\quad$ Middle-aged GHR-KO on I.F. ad libitum-fed Glucose Tolerance Test}

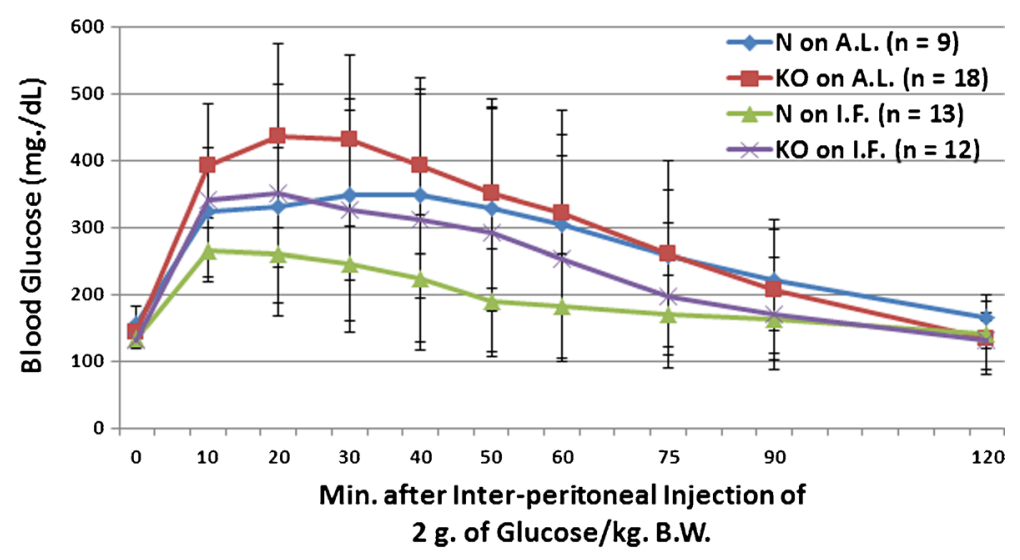

b Middle-aged GHR-KO on I.F. Fasted Glucose Tolerance Test

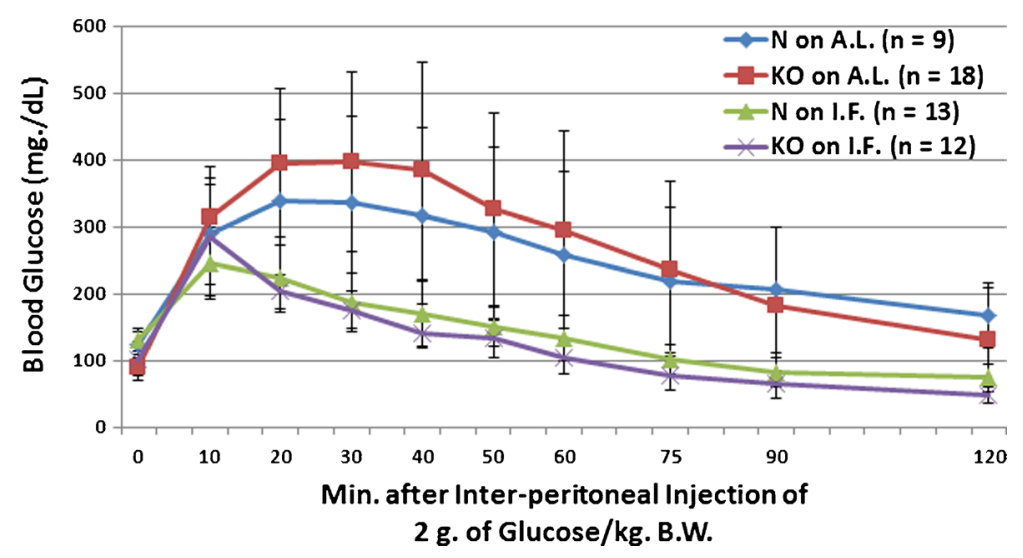

Fig. 2 Short-term IF improved dynamics of blood glucose assimilation in middle-aged GHR-KO females and old Ames Dwarf males. a AL-fed glucose tolerance test (absolute values, with statistical analysis table) showing detrimental effect of $\mathrm{KO}$ phenotype and beneficial effects of short-term IF diet on both middle-aged $\mathrm{N}$ and middle-aged KO female mice. b Fasted glucose tolerance test (absolute values, with statistical analysis table) showing beneficial effects of short-term IF diet on both middle-aged $\mathrm{N}$ and middle-

into old age ( $p=0.0175$; Fig. $3 b)$. IF improved insulin sensitivity for normal $(\mathrm{N})$ old males $(p=0.0189)$, as well as already insulin-sensitive old Df males $(p=0.0545$; Fig. 3b); furthermore, the combination of Ames Dwarfism and IF dieting had a greater effect on increasing insulin sensitivity than either intervention individually ( $p=0.0174$; Fig. $3 b)$. Once again, here no diet-generated differences in BW were noticed (Fig. S11). aged KO female mice. c AL-fed glucose tolerance test (absolute values, with statistical analysis table) showing beneficial effect of IF diet on old $\mathrm{N}$ littermate control male mice. d Fasted glucose tolerance test (absolute values, with statistical analysis table) showing detrimental effect of Df phenotype, and beneficial effect of IF diet on old Df male mice. All measures of central tendency are arithmetic means, and all depictions of variation (error bars) represent standard deviations $(S D)$ (see also Figs. S1-S8)

Pyruvate conversion tests in middle-aged GHR-KO or old Ames Df mice

Excessive generation of glucose in hepatocytes is a potent mechanism for induction of deleterious hyperglycemia in T2DM patients (Klover and Mooney 2004); and the most effective and popular drug treatment for T2DM-related hyperglycemia (Metformin) works chiefly by suppressing hepatic gluconeogenesis (Alengrin 


\section{C \\ Old Ames Dwarf on I.F.}

A.L.-fed Glucose Tolerance Test

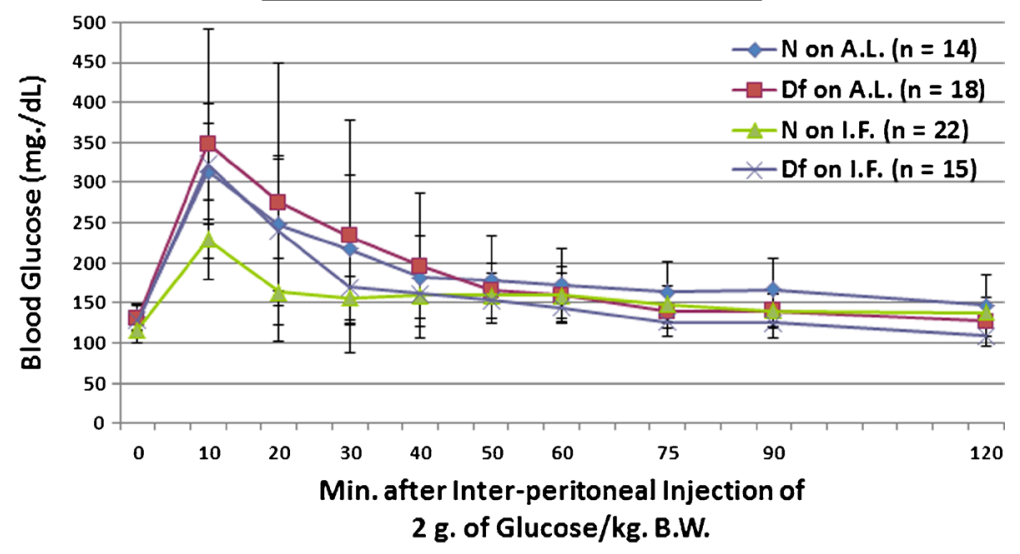

d

Old Ames Dwarf on I.F. Fasted Glucose Tolerance Test

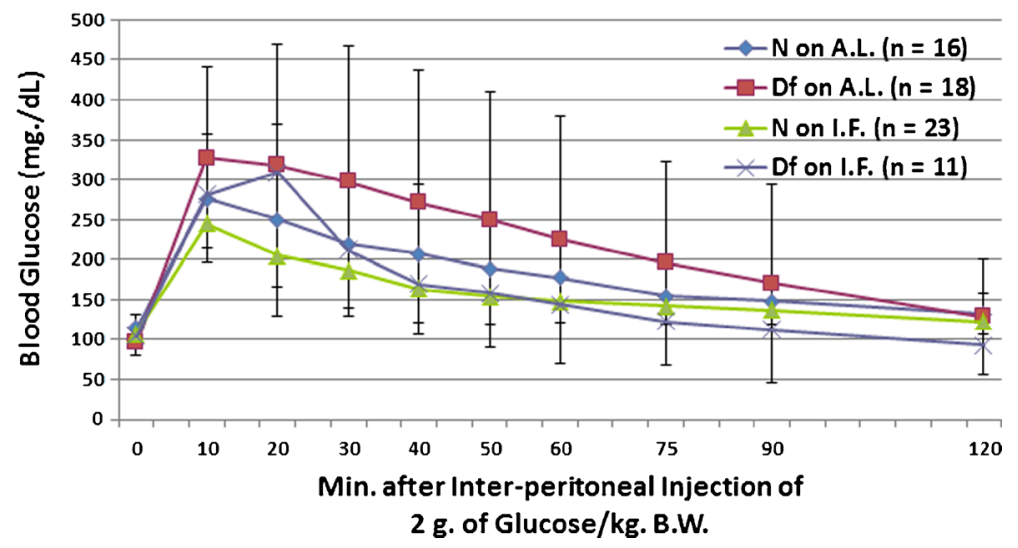

Fig. 2 (continued)

et al. 1987; Hundal et al. 2000; Viollet et al. 2012). Yet, to the best of our knowledge, the contribution of inappropriately increased gluconeogenic production to the age-related deterioration of glucose homeostasis has not been systematically investigated. Hepatic gluconeogenic potential has also not been investigated for either long-lived GH signaling-deficient mouse mutants herein utilized, or for IF mice. Thus, we explored whether $2 \mathrm{~g}$ of sodium pyruvic acid (per $\mathrm{kg}$ of $\mathrm{BW}$ ) differentially affected blood glucose production in middle-aged $\mathrm{KO}$ mice on IF or their controls. We found that $\mathrm{KO}$ females had a greater ability to convert pyruvate to glucose than their $\mathrm{N}$ counterparts $(p=0.0533)$, and that IF dampened both this hypersensitivity to the presence of pyruvate in middle-aged GHR-KO females $(p=0.0285)$, as well as the normal rate of glucose production exhibited by the untreated middle-aged $\mathrm{N}$ females ( $p=0.0318$; Fig. 3c). Moreover, the combined effect of $G h r / b p$ disruption and IF decreased the glucose production potential of middleaged littermate control females ( $p=0.0011$; Fig. $3 c)$. IF did not alter the fasting body weight determined immediately preceding these tests (Fig. S13).

We also looked into whether old Df males placed on a short duration of IF differentially regulated their ability to convert pyruvate to glucose. Relative to their littermate controls on $\mathrm{AL}$, old Ames Dwarfs had a heightened output of glucose after pyruvate administration $(p=0.05$ for old Ames Dwarf males on AL, $p=0.0512$ for old Ames Dwarf males on IF), whilst IF had no effect on that feature for either Df males or their 

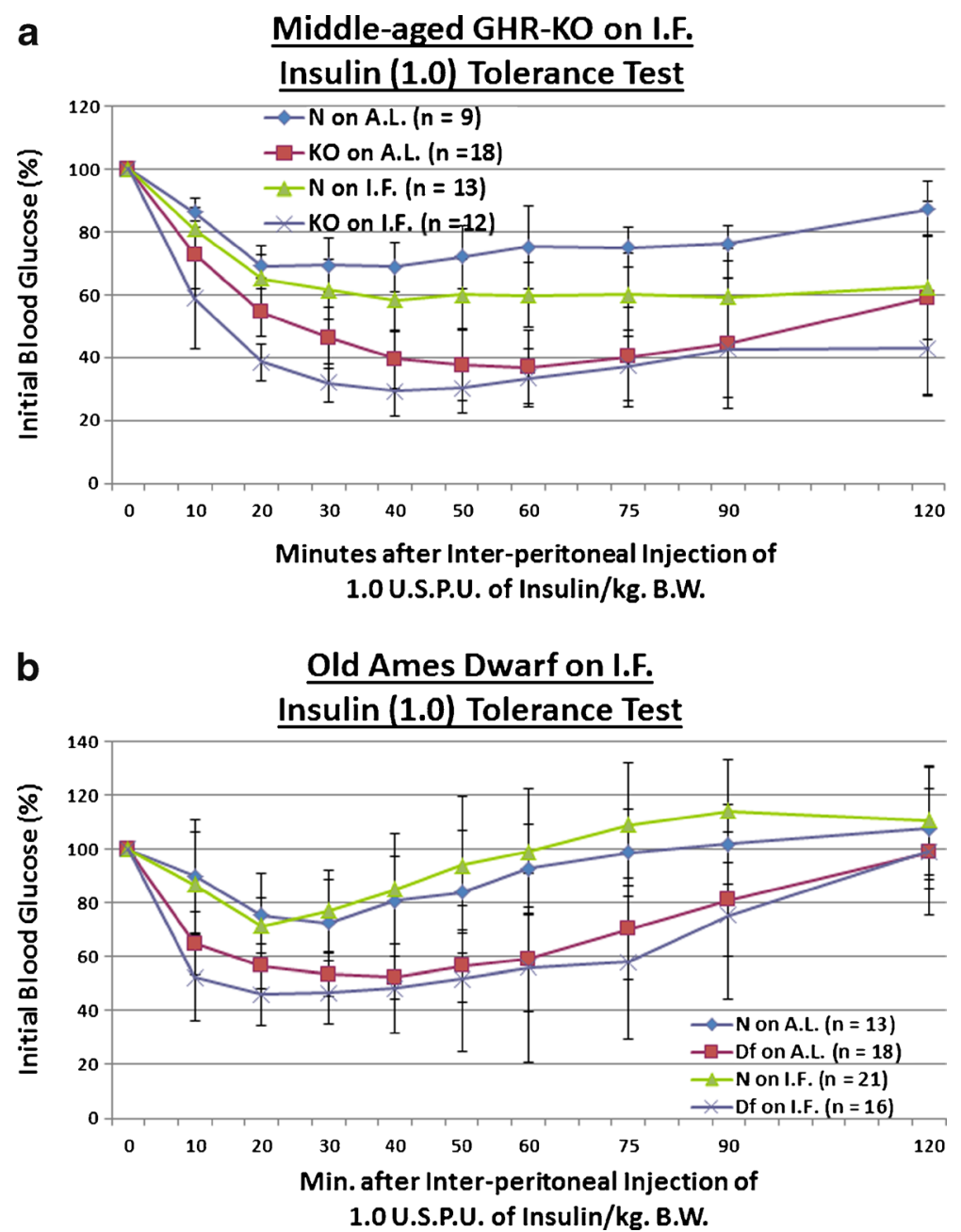

Fig. 3 Short-term IF improved kinetics of insulin-mediated blood glucose clearance in middle-aged GHR-KO females and old Ames Dwarf males, and decreased gluconeogenesis in middle-aged GHR-KO females. a Insulin tolerance test (normalized values, with statistical analysis table) showing beneficial effect of KO phenotype and a combined sensitizing effect of both factors on middleaged $\mathrm{N}$ littermate control females. b Insulin tolerance test (normalized values, with statistical analysis table) showing sensitizing effect of Df phenotype, sensitizing effects of IF on both old $\mathrm{N}$

littermate $(\mathrm{N})$ controls (Fig. 3d). Of particular note is that IF did not affect BW for this test either (Fig. S15).

Determinations of AL-fed or fasted unstressed glycemic load in middle-aged GHR-KO or old Ames Df mice

Even when detected under non-challenging circumstances, inappropriate blood glucose regulation is males and old Df mutant males, and a combined sensitizing effect of both factors on old $\mathrm{N}$ males. c Pyruvate conversion test (normalized values, with statistical analysis table) showing promoting effect of KO phenotype and repressive effects of short-term IF diet on both middle-aged $\mathrm{N}$ and middle-aged $\mathrm{KO}$ females. d Pyruvate conversion test (normalized values, with statistical analysis table) showing promoting effect of Df phenotype. All measures of central tendency are arithmetic means, and all depictions of variation (error bars) represent standard deviations $(S D)$ (see also Figs. S9-S16)

correlated with adverse clinical outcomes (Moghissi 2010; Farrokhi et al. 2011). Both AL-fed and fasted blood glucose levels were assessed multiple times for both middle-aged GHR-KO females on IF and old Ames Df male mice on IF As the relative results exhibited little variability, we report representative results here. When given AL access to food, neither homozygosity for the Ghr/bp gene disruption nor homozygosity for the $d f$ allele affected blood glucose values at the 

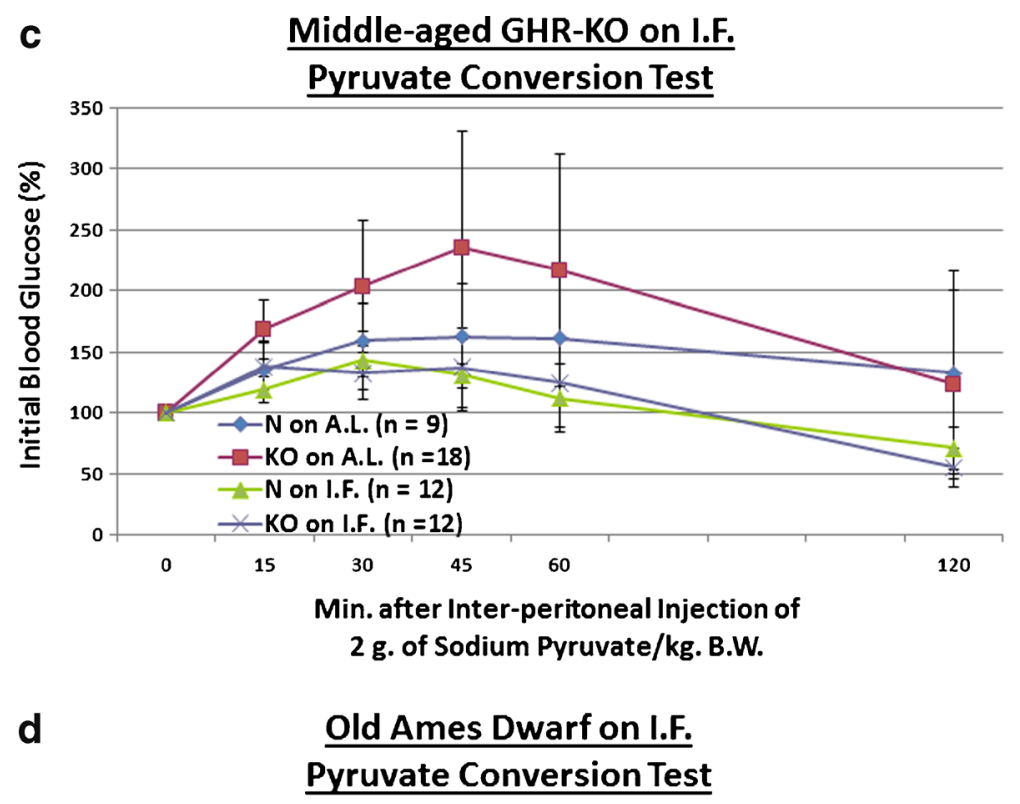

Fig. 3 (continued)

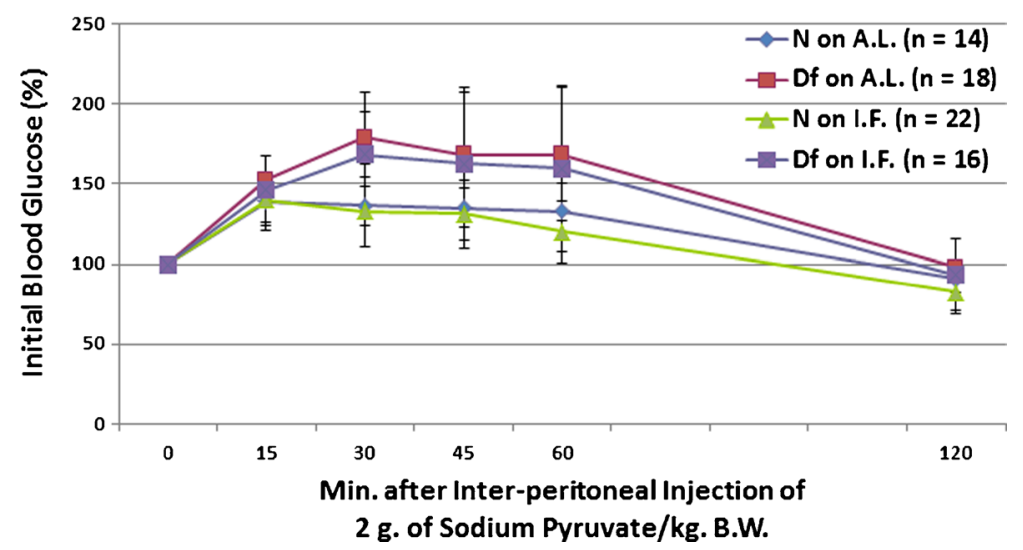

respective ages examined (Fig. $4 \mathrm{a}$ and c). In contrast, IF lowered AL-fed blood glucose significantly for littermate controls of both stocks $(p=0.0059$ for middle-aged female $\mathrm{N}$ mice of the GHR-KO Stock [Fig. 4a]; $p=$ 0.0139 for old male $\mathrm{N}$ mice of the Ames Df Stock [Fig. 4c]), as well as for middle-aged female GHR-KO mutants $(p=0.0157$ relative to female $\mathrm{KO}$ mutants on AL; Fig. 4a). In sync, a combined effect of the Ghr/bp gene disruption and IF on AL-fed blood glucose was documented ( $p=0.0086$; Fig. $4 \mathrm{a}$ ).

In animals fasted for $\sim 16 \mathrm{~h}$ before assessment, both mutants had substantial decreases in blood glucose concentrations relative to their littermates $(p=0.0164$ for old male Ames Df mice; Fig. 4b and d). IF surprisingly raised fasted blood glucose for both middle-aged female
GHR-KO mice $(p=0.0333)$ and their littermate controls $(p=0.0498)$ (confirmed in two independent assessments; Fig. 4b), whilst lowering fasted blood glucose for the littermate controls of old Ames Df males ( $p=0.047$; Fig. $4 d)$.

Studies on animal subjects subjected to prolonged (4660 weeks for GHR-KO, 58-69 weeks for Ames Df) IF

Glucose tolerance in old GHR-KO or oldest-old Ames Df mice

After the animals were exposed to IF for a substantial sector of late life, we re-investigated the same blood glucose homeostasis regulation parameters in the two 
stocks of slow-aging dwarf mice. The experiments conducted during this period test (1) the regulation of blood glucose in old or oldest-old mice of any type, (2) the differential control of blood glucose dynamics in old or oldest-old dwarf mice, relative to their appropriate littermate controls, (3) the effects of longer-term IF on regulation of blood glucose, and (4) any interactive result of an anti-aging phenotype and the anti-aging diet under study on the examined parameters.

We examined whether the $G h r / b p$ gene disruption, or $\sim 58$ weeks of IF, affects absorption of $2 \mathrm{~g}$ of glucose (per kilogram of BW) in old mice. For assessments conducted after a fasting, we found that $\mathrm{KO}$ females remain innately glucose-intolerant relative to $\mathrm{N}$ controls into old age $(p=0.0486$ for $\mathrm{KO}$ on $\mathrm{AL}$ [vs. $\mathrm{N}$ on $\mathrm{AL}$ ] and $p=$ 0.0302 for $\mathrm{KO}$ on IF [vs. N on AL]; Fig. 5b). Old female littermate controls, when treated with $I F$, markedly improved clearance of blood glucose during testing for which they were fasted for approximately $16 \mathrm{~h}$ beforehand ( $p=0.038$; Fig. 5b). As an important dissociation based on testing paradigm, no phenotype- or diet-related effects occurred during $A L-f e d$ glucose tolerance testing of old GHR-KO Stock mice (Fig. 5a). As an important note, no diet-caused differences in body weight were present at the time of testing for either AL-fed (Fig. S17) or fasted (Fig. S19) blood glucose tolerance.

We also investigated whether the Proplgene mutation, or $\sim 46$ weeks of IF, affects uptake of a 2 -g glucose (per kg BW) bolus in oldest-old mice. We tentatively found that oldest-old Df male mice are glucoseintolerant relative to $\mathrm{N}$ counterparts only under postfasting conditions ( $p=0.0844$; Fig. $5 \mathrm{~d})$; in the same testing, we paradoxically discovered that oldest-old Df males on IF are made even more glucose-intolerant, relative to their $\mathrm{N}$ counterparts on $\mathrm{AL}$, by the restrictive $\operatorname{diet}(p=0.028$; Fig. 5 d). Consistent with this paradox, IF worsened the glucose handling of oldest-old Df males ( $p=0.0462$ for testing conducted after AL feeding [Fig. $5 \mathrm{c}$ ], $p=0.0046$ for testing conducted after a fast [Fig. 5d]). Importantly, no diet-related differences in body weight were detected at the time of testing for either AL-fed (Fig. S21) or fasted (Fig. S23) blood glucose tolerance.

\section{Insulin tolerance tests in old GHR-KO or oldest-old Ames Df mice}

We explored the effect of the $G h r / b p$ insertional mutation, or the longer-term duration of IF, upon sensitivity to a $1,0.3$, or $0.1 \mathrm{USPU}$ of insulin $/ \mathrm{kg}$ BW bolus. We observed that old $\mathrm{KO}$ females maintained the enhanced insulin sensitivity documented in young adulthood and middle age ( $p=0.0551$ at 0.3 USPU of insulin $/ \mathrm{kg} \mathrm{BW}$ [Fig. 6b], $p=0.0335$ for 0.1 USPU insulin $/ \mathrm{kg} \mathrm{BW}$ [Fig. 6c]). As for IF, it improved insulin sensitivity even in old $\mathrm{N}$ females $(p=0.0354$ for $0.3 \mathrm{USPU} / \mathrm{kg} \mathrm{BW}$ [Fig. 6b], $p=0.0436$ for $0.1 \mathrm{USPU} / \mathrm{kg} \mathrm{BW}$ [Fig. 6c]). Amazingly, IF further potentiated the insulin sensitivity of old $\mathrm{KO}$ females, relative to $\mathrm{N}$ controls on $\mathrm{AL}$ ( $p=0.0552$ at $1 \mathrm{USPU} / \mathrm{kg} \mathrm{BW}$ [Fig. 6a], $p=0.0438$ at $0.3 \mathrm{USPU} / \mathrm{kg}$ BW [Fig. $6 \mathrm{~b}$ ], $p=0.0256$ for $0.1 \mathrm{USPU} / \mathrm{kg}$ BW [Fig. 6c]). Extraordinarily, old IF-treated KO females were even more insulin-sensitive than old AL-fed KO females ( $p=0.0258$ for 0.3 USPU $/ k g$ BW [Fig. 6b], $p=0.0392$ for 0.1 USPU $/ \mathrm{kg} \mathrm{BW}$ [Fig. 6c]). These results were largely independent of the strength of the insulin stimulus, as similar results were obtained over the orderof-magnitude dosage range. No diet-induced differences in BW were noted (Figs. S25, S27, and S29).

Oldest-old Df males on IF were also assessed for insulin sensitivity to $1,0.3$, or 0.1 USPU of insulin. In stark surprise, we observed that oldest-old Df males are not insulin-sensitive relative to their littermate controls $(\mathrm{N})$, and are in fact insulin-resistant $(p=0.0432$ at 1 USPU of insulin $/ \mathrm{kg} \mathrm{BW}$ [Fig. 6d], $p=0.054$ at 0.1 USPU insulin/kg BW [Fig. 6f]). Continuing with this surprising theme, IF also worsened insulin sensitivity in oldest-old $\mathrm{N}$ males $(p=0.0424$ for $1 \mathrm{USPU} / \mathrm{kg} \mathrm{BW}$ [Fig. 6d], $p=0.0463$ for $0.3 \mathrm{USPU} / \mathrm{kg} \mathrm{BW}$ [Fig. 6e], $p=0.0096$ for $0.1 \mathrm{USPU} / \mathrm{kg} \mathrm{BW}$ [Fig. 6f]). IF also increased the insulin-resistance of oldest-old Df males relative to $\mathrm{N}$ males on $\mathrm{AL}$ ( $p=0.0333$ for $0.3 \mathrm{USPU} / \mathrm{kg}$ BW; Fig. 6e). These data were largely independent of the strength of the insulin stimulus, as similar results were obtained over the order-of-magnitude dose range. Once again, here no diet-stimulated differences in BW were noticed (Figs. S31, S33, and S35).

Pyruvate conversion tests in old GHR-KO or oldest-old Ames Df mice

We evaluated whether $2 \mathrm{~g}$ of sodium pyruvic acid (per $\mathrm{kg}$ of $\mathrm{BW}$ ) differentially affected hepatic blood glucose production in old $\mathrm{KO}$ mice, normal controls, or either phenotype during longer-term IF We found that old $\mathrm{KO}$ females continued to convert more pyruvate to glucose than their $\mathrm{N}$ counterparts $(p=0.034)$ (Fig. 6g). IF tentatively 


\section{a Middle-aged GHR-KO on I.F.}

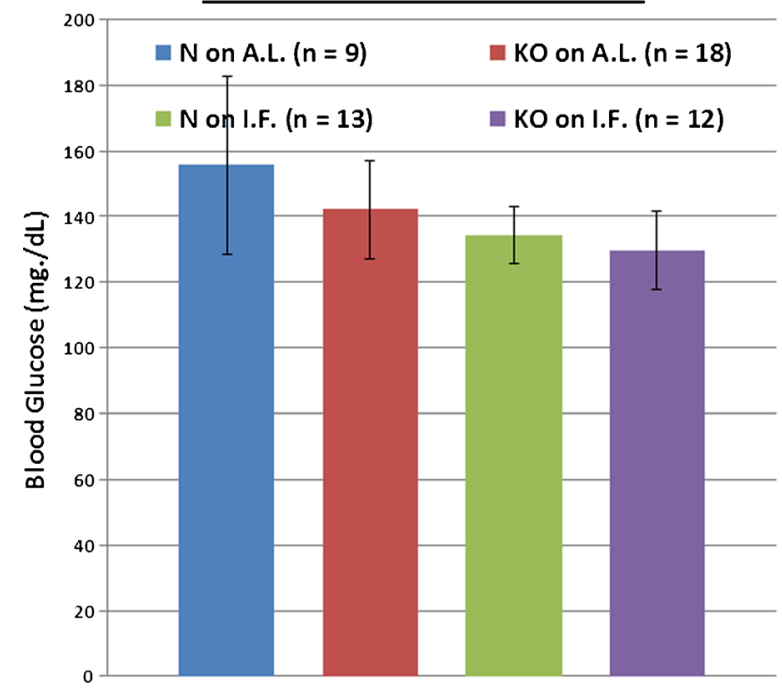

b

Middle-aged GHR-KO on I.F. Fasted Blood Glucose

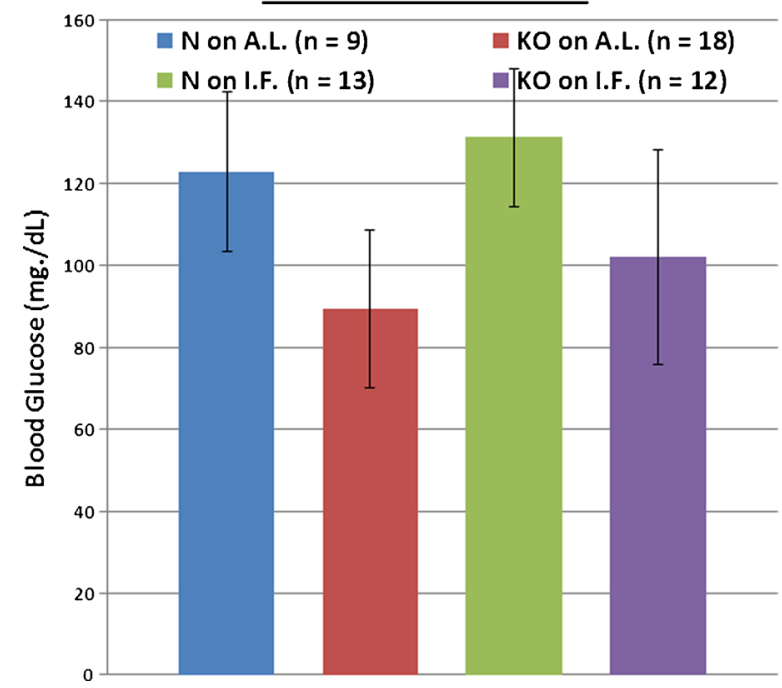

Fig. 4 Differential effects of phenotype or diet on AL-fed or fasted blood glucose concentrations at middle-aged (for GHR-KO Mice) or old (for Ames Dwarfs) age range. a AL-fed testing of middleaged GHR-KO female mice after short-term IF (with statistical analysis table) showing blood glucose-lowering effects of IF diet for both middle-aged $\mathrm{N}$ female littermate mice and middle-aged female KO mutants, and an additive (lowering) effect of $\mathrm{KO}$ phenotype and IF diet on middle-aged $\mathrm{N}$ female littermate controls. b Fasted assessment of middle-aged GHR-KO females after shortterm IF (with statistical analysis table) exhibiting blood glucose-
C

Old Ames Dwarf on I.F.

\section{A.L.-fed Blood Glucose}

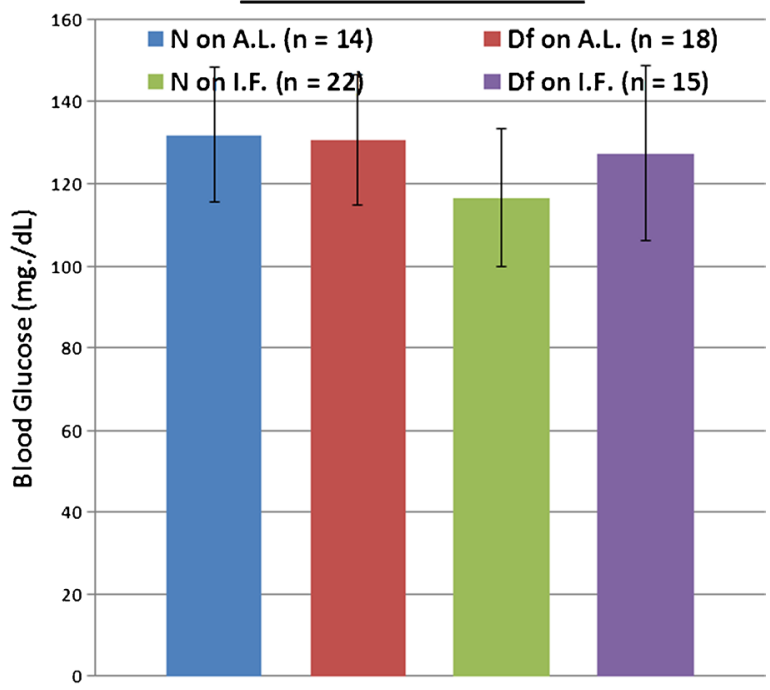

d

Old Ames Dwarf on I.F. Fasted Blood Glucose

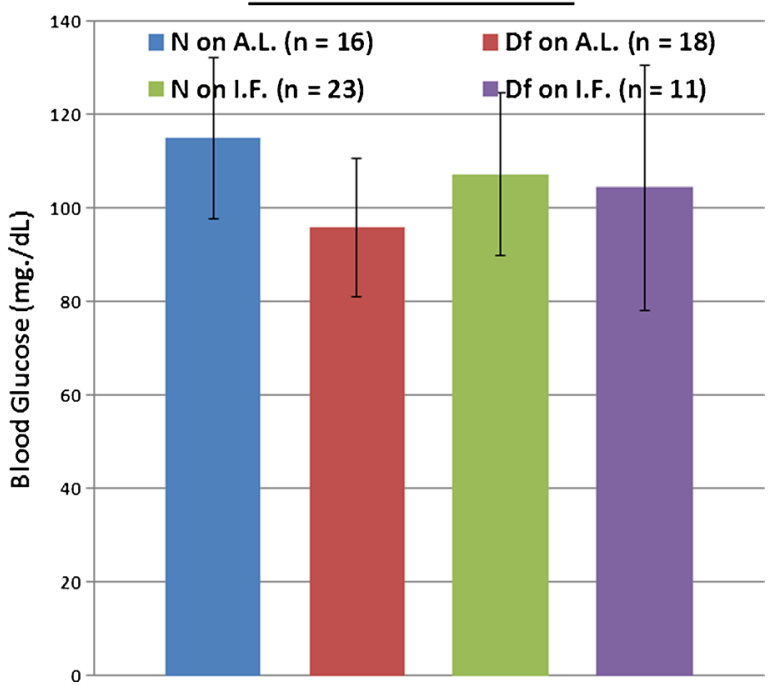

increasing effects of IF diet for both middle-aged $\mathrm{N}$ female littermates and middle-aged $\mathrm{KO}$ female mutants. c AL-fed testing of old Ames Dwarf male mice after short-term IF (with statistical analysis table) displaying blood glucose-lowering effect of IF diet on old $\mathrm{N}$ littermate males. $\mathbf{d}$ Fasted assessment of old Ames Dwarf males after short-term IF (with statistical analysis table) demonstrating blood glucose-lowering effect of Df phenotype as well as beneficial effect of IF diet on old $\mathrm{N}$ littermate males. All measures of central tendency are arithmetic means, and all depictions of variation (error bars) represent standard deviations $(S D)$ 
a

Old GHR-KO on I.F.

\section{A.L.-fed Glucose Tolerance Test}

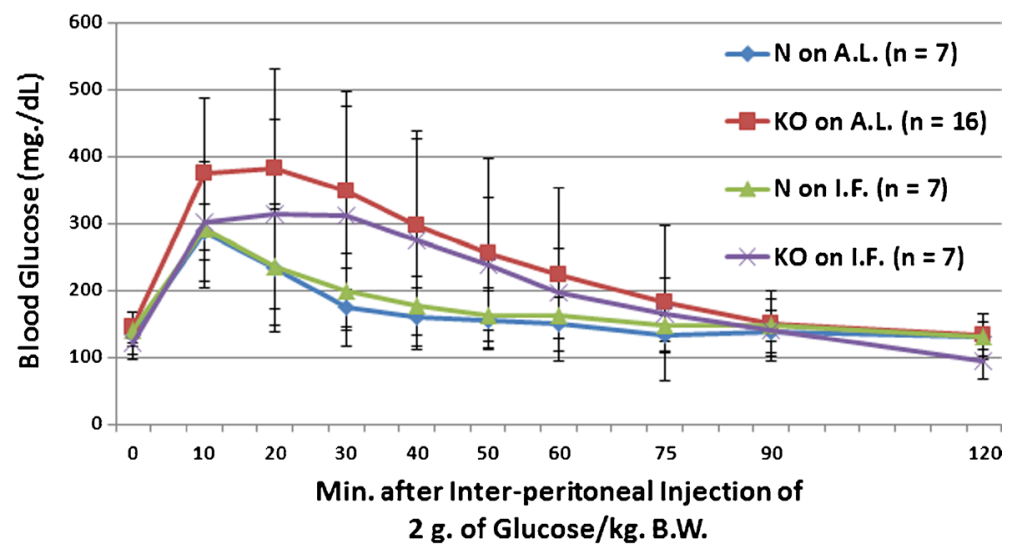

b

Old GHR-KO on I.F. Fasted Glucose Tolerance Test

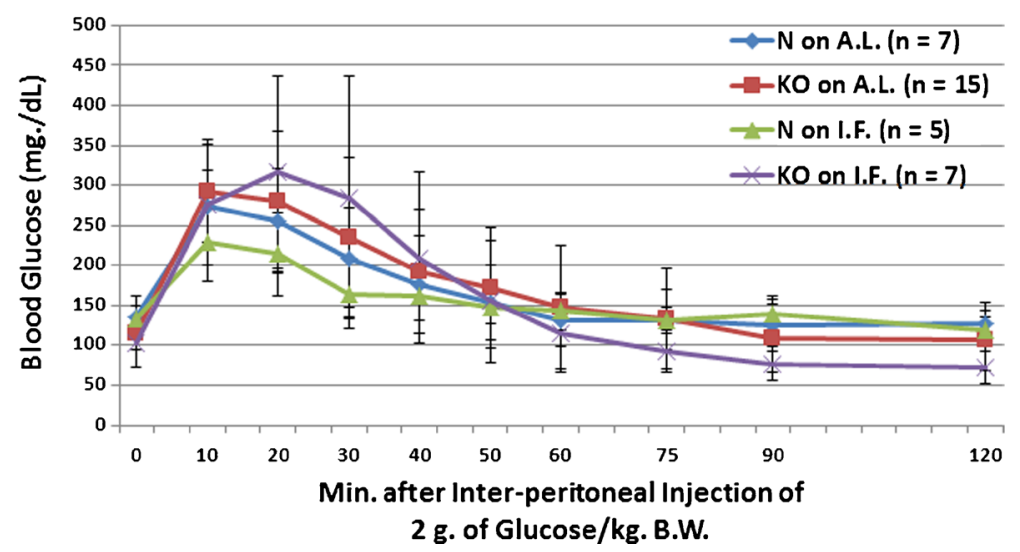

Fig. 5 Longer-term IF sustained improved dynamics of blood glucose incorporation in old GHR-N females, but worsened it in old GHR-KO females and oldest-old Ames Dwarf males. a ALfed glucose tolerance test (absolute values, with statistical analysis table) showing detrimental effect of KO phenotype. b Fasted glucose tolerance test (absolute values, with statistical analysis table) showing detrimental effect of KO phenotype and beneficial effect of IF diet for old littermate control (N) female mice, yet a detrimental effect of IF for old female GHR-KO mice. c AL-fed

dampened this hypersensitivity to pyruvate in old female KO mice $(p=0.1325)$, but did not affect the normal degree of glucose production exhibited by the old $\mathrm{N}$ females (Fig. 6g) as it had in middle age (Fig. 3c). IF did not affect the fasting body weight determined immediately preceding these tests (Fig. S37). glucose tolerance test (absolute values, with statistical analysis table) showing detrimental effect of IF diet for oldest-old Ames Dwarf mutant males. d Fasted glucose tolerance test (absolute values, with statistical analysis table) showing detrimental effect of Df phenotype and deleterious effect of IF diet on oldest-old Df mutant males. All measures of central tendency are arithmetic means, and all depictions of variation (error bars) represent standard deviations $(S D)$ (see also Figs. S17-S28.)

We also checked whether oldest-old Df males, their littermate controls, or either sustained on longer-term IF differentially regulated their ability to convert pyruvate to glucose. We found no phenotype- or diet-related differences in conversion of pyruvic acid to glucose (Fig. 6h). IF did not induce BW differences for this test, either (Fig. S39). 


\section{C}

Oldest-Old Ames Dwarf on I.F.

A.L.-fed Glucose Tolerance Test

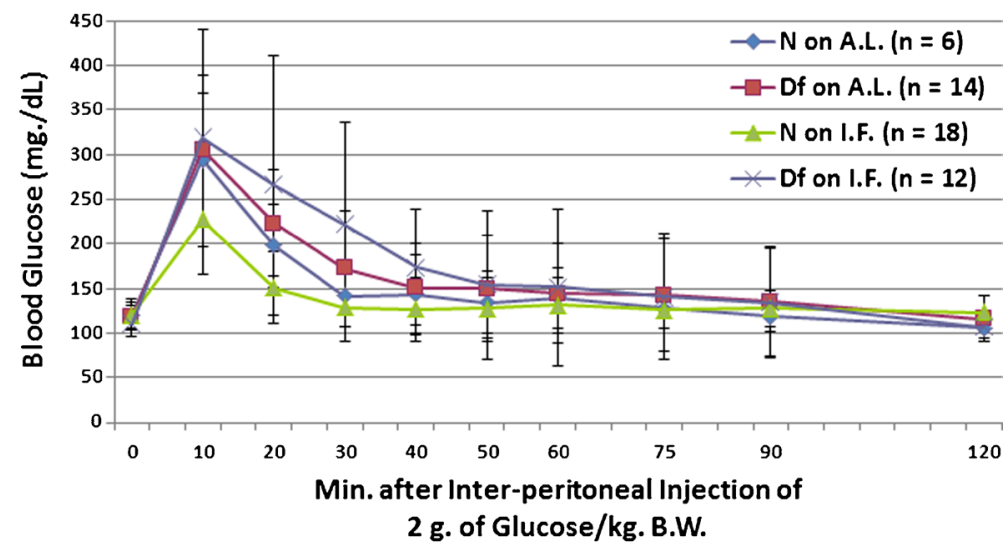

d

Oldest-Old Ames Dwarf on I.F.

Fasted Glucose Tolerance Test

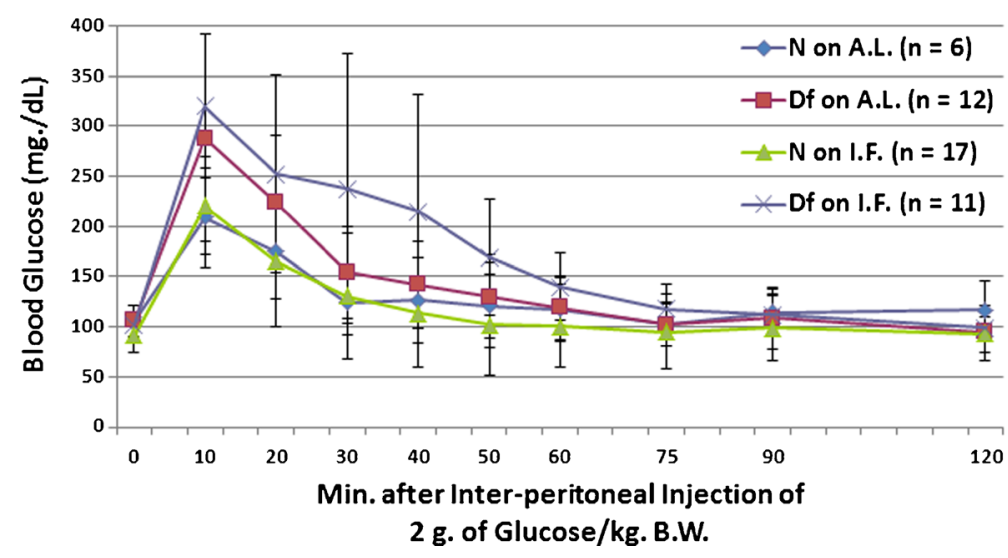

Fig. 5 (continued)

Unfettered blood glucose levels in old GHR-KO or oldest-old Ames Df mice

When AL-fed, neither homozygosity for the Ghr/bp gene disruption nor homozygosity for the $d f$ allele affected blood glucose values at old or oldest-old ages, respectively (Fig. 7a and c). Contrary to results at earlier ages, IF by itself did not alter ALfed blood glucose for littermate controls or for either of the mutants (Fig. 7a and c). Yet, the combined effect of the $G h r / b p$ gene disruption and IF decreased AL-fed blood glucose values in old GHR-KO females $(p=0.0246$ for old $\mathrm{N}$ females on $\mathrm{AL}$ vs. old $\mathrm{KO}$ females on IF) (Fig. 7a).
In fasted animals, neither old GHR-KO females nor oldest-old Df males had lower blood glucose concentrations than their littermates. Also in contrast to the results at earlier ages, IF did not lower blood glucose in this circumstance for either dwarf or normal-sized mice (Fig. $7 b$ and d).

\section{Discussion}

In this report, we investigate the effects of longevityconferring genetic (GH signaling deficiency) and/or dietary (IF) interventions on aging-related changes in the ability to maintain euglycemia. We find that either of 
two genetic alterations ameliorates fasting hyperglycemia. Additionally, both longevity-inducing mutations improve insulin sensitivity in old age. Strikingly, we observe major improvements in blood glucose homeostatic regulation by IF: IF improves AL-fed hyperglycemia, glucose intolerance, insulin sensitivity, and reduces hepatic gluconeogenesis in aging mutant and normal mice. Beneficial additive effects are observed for most of the measured parameters.

As a general interpretation, the results from this study detailing the beneficial effects of lifelong GH signaling deficiency for the endocrinological function of middleaged to oldest-old mice are consistent with those observed at earlier ages. The dwarfing phenotypes substantially reduced fasted blood glucose concentrations, heightened insulin-mediated glucose clearance, and enhanced pyruvate conversion; moreover, and very importantly, this was achieved in a stock-independent and quasi-gender-independent fashion. This persistence of the effect of these genetic lesions is important for theses suggesting that the endocrinological abnormalities in this group of animals are in any way related to their increased survivorship. What is more, these phenotype-specific results show that these mutants are promising models for dysfunction-free aging of the endocrine system. The preserved insulin sensitivity with aging, in particular, suggests that the standard decline in insulin sensitivity with aging in humans can be prevented or reversed. Future studies with FDA-approved GH signaling antagonists, whether Octreotide (Cozzi and Attanasio 2012) or Pegvisomant (van der Lely et al. 2012), introduced late in life should address whether the observed benefits can be achieved in a treatment paradigm.

The brief IF regimen substantially reduced AL-fed blood glucose concentrations, markedly improved glucose disposal, heightened insulin-mediated glucose clearance, and attenuated pyruvate conversion; furthermore, and very importantly, this was achieved in a stock-independent and quasi-gender-independent fashion. This rapid physiological amelioration underscores the power of dietary restriction, particularly that with a late-life adoption, as being highly effective in treating aging-associated dysfunctions or morbidities. That these healthspan benefits were achieved in a relatively short period should aid their adoption by patients, as positive outcomes from labors and abstemiousness would presumably serve as psychological spurs. Considering that clinical IF would be a dietary intervention that does not require the development of any pharmaceutical aid or novel technology, these results are very translatable.

An aspect of this study that we believe deserves special emphasis is the inclusion of three age groups, including 35-month-old GHR-KO animals. This corresponds to approximately $81 \%$ or $109 \%$ of the life expectancy of mutants or littermate controls, respectively (Arum et al. 2009). This serves to reiterate the accomplishment of seminal characterization of blood glucose regulation in oldest-old subjects, and that of investigation of the effects of longevity-conferring alleles and/or diets on that regulation in those oldest-old animals. This conscientious feature of this study may beneficially inform geriatric care.

Distinguishing changes that may represent causes of functional decline or increased probability of morbidity or mortality from those that are merely an effect of prior, causative macromolecular or physiological derange-

Fig. 6 Longer-term IF sustained improved kinetics of insulinmediated blood glucose clearance and gluconeogenesis in Old GHR-KO females, but largely desensitized oldest-old Ames Dwarf males to insulin's effects on blood glucose. a The 1.0 USPU insulin tolerance test (normalized values, with statistical analysis table) showing a combined (sensitizing) effect of both KO phenotype and IF diet on old $\mathrm{N}$ female littermates. b The 0.3 USPU insulin tolerance test (normalized values, with statistical analysis table) showing sensitizing effect of KO phenotype, sensitizing effects of IF diet on both old female $\mathrm{N}$ controls and old female KO mutants, and sensitizing benefit of both KO phenotype and IF diet on old female $\mathrm{N}$ littermates. $\mathbf{c}$ The 0.1 USPU insulin tolerance test (normalized values, with statistical analysis table) showing sensitizing effect of KO phenotype, sensitizing effects of IF diet on both old female $\mathrm{N}$ mice and old female KO mutants, and sensitization benefit of both $\mathrm{KO}$ phenotype and IF diet on old $\mathrm{N}$ females. d The 1.0 USPU insulin tolerance test (normalized values, with statistical analysis table) showing de-sensitizing effect of Df phenotype, de-sensitizing effect of IF diet on oldest-old $\mathrm{N}$ males, yet sensitizing effect of IF on oldest-old Df male mice. e The 0.3 USPU insulin tolerance test (normalized values, with statistical analysis table) showing de-sensitizing effects of IF on both oldestold $\mathrm{N}$ male mice and oldest-old male Df mutants, as well as desensitizing effect of a combination of both factors on oldest-old $\mathrm{N}$ littermate control males. f The 0.1 USPU insulin tolerance test (normalized values, with statistical analysis table) showing desensitizing effect of Df phenotype and de-sensitizing effect of IF on oldest-old $\mathrm{N}$ littermate males. g Pyruvate conversion test (normalized values, with statistical analysis table) showing promoting effect of $G h r / b p$ gene disruption and repressive effect of IF diet for female GHR-KO mice. h Pyruvate conversion test (normalized values, with statistical analysis table) showing no effect of either Df phenotype or IF on oldest-old males of either phenotype. All measures of central tendency are arithmetic means, and all depictions of variation (error bars) represent standard deviations $(S D)$ (see also Figs. S29-S40) 


\section{a}

Old GHR-KO on I.F. Insulin (1.0) Tolerance Test

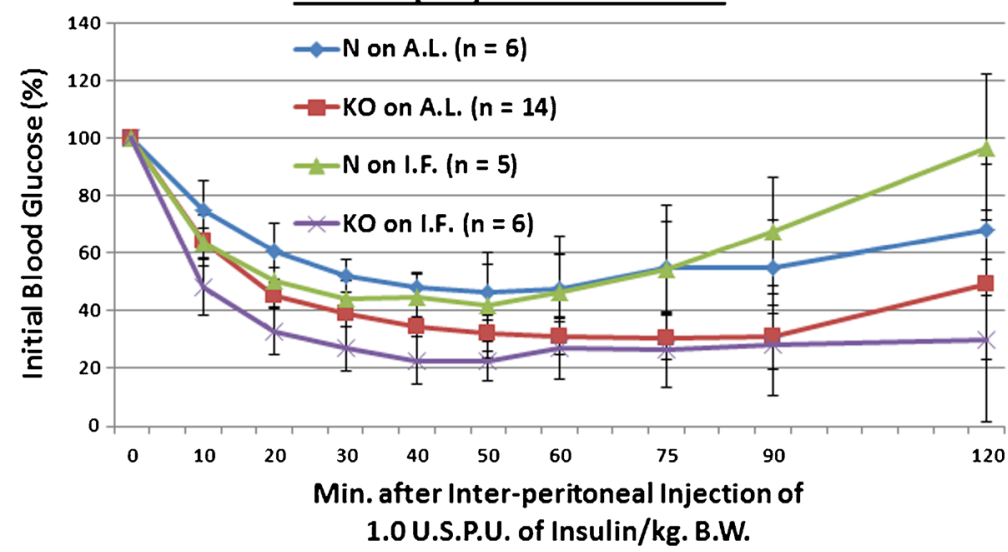

b

Old GHR-KO on I.F. Insulin (0.3) Tolerance Test

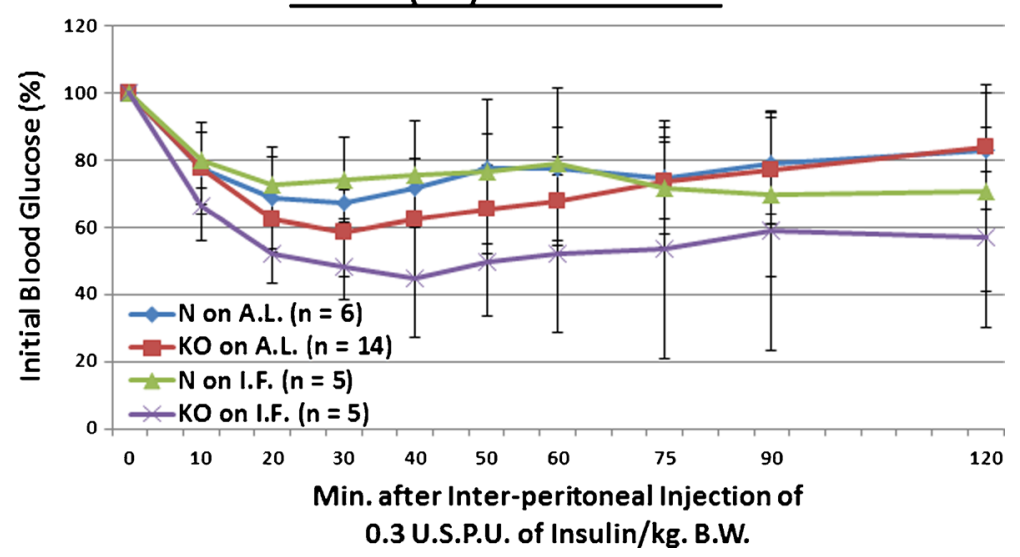

ments is crucial for future interventional studies. For these reasons, studies such as this one that investigate interesting gerontological questions in middle-aged, as well as old, organisms are critical for developing more comprehensive schematics of differences between groups of interest without introducing unnecessary confounds (Finch 2009).

The clinical and public health importance of agingrelated development of hyperinsulinemia and insulin resistance is difficult to overemphasize. Hyperglycemia is positively correlated with increased immune function markers, such as the pro-inflammatory cytokines tumor necrosis factor-alpha (TNF- $\alpha$ ) and interleukin-6 (IL-6), which seem to mediate a worsening of clinical outcomes (Collier et al. 2008). As another immunological detriment to poor endocrinological function, blood glucose concentration is positively correlated with pneumonia incidence; prolonging hospitalization, and increasing complications and risk of mortality (Salonen et al. 2012). It has been known for decades that diabetics are more susceptible to developing periodontitis, and respond less well to its treatment and management (Pucher and Stewart 2004). What is more, hyperglycemia positively correlates with poor clinical outcomes (i.e., increased morbidity, length of stay, and mortality) following coronary artery bypass graft $(\mathrm{CABG})$ surgeries (Lazar 2012). These limited representative examples are mentioned to stress the wide-ranging clinical decrements that are associated with, and thus may result in part due to, poor glycemic control. Considering the marked decline in immune system efficacy with aging and the increased 

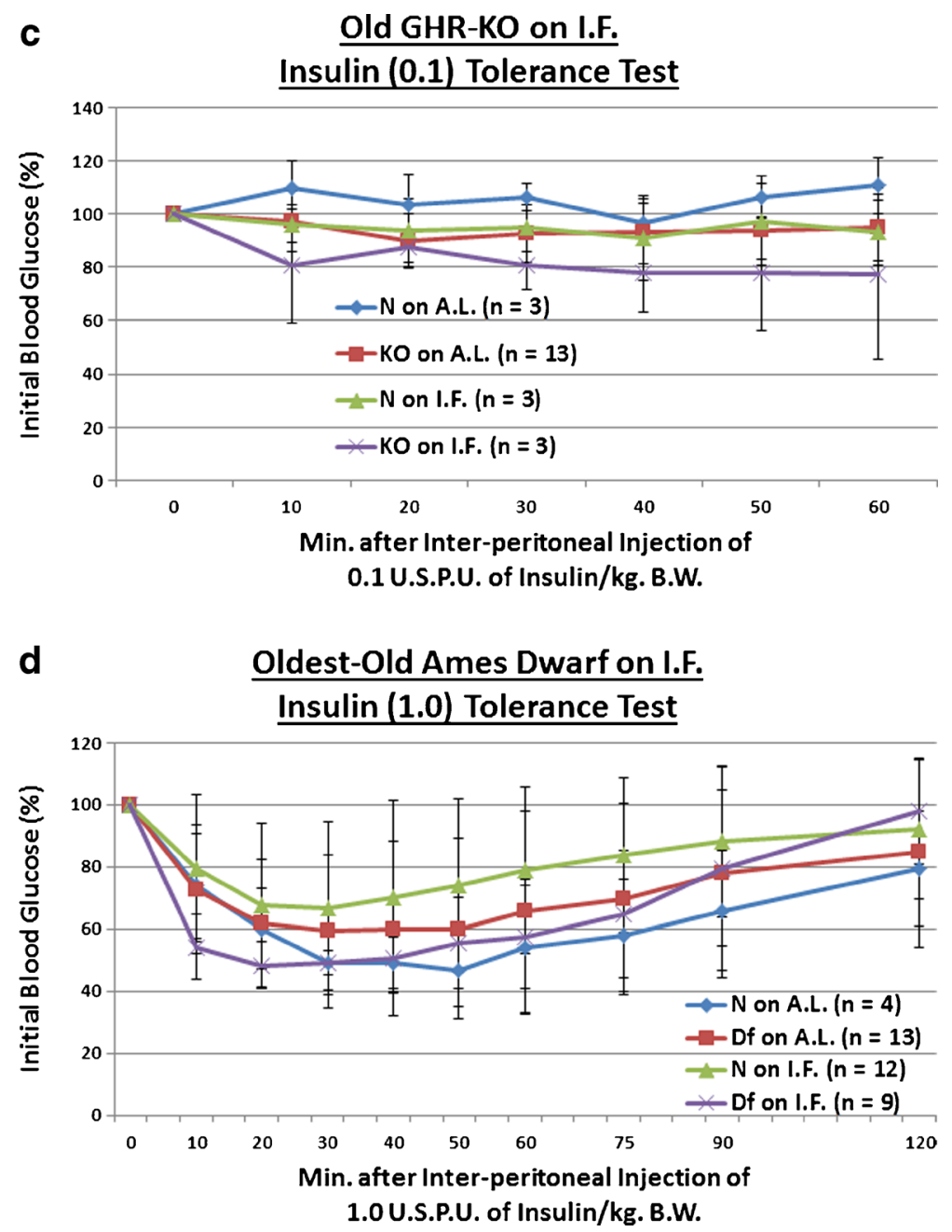

Fig. 6 (continued)

incidence of $\mathrm{CABG}$ procedures with advancing age, these general health concerns are of magnified consequence for geriatric populations.

Benefits of CR begun late in life on mortality and lifespan are well documented in Drosophila melanogaster (Mair et al. 2003), but there is less data for mammals. To the best of our knowledge, there are no data on the effects of IF induced late in life on survivorship, for any species. Benefits of adult-onset CR on glucose homeostasis are well documented for people (Fontana et al. 2004; Heilbronn et al. 2006; Rochon et al. 2011), but the effects of IF on glucose homeostasis in middle-aged or older subjects have not been explored. Considering the differences in (1) body composition, (2) physiology, (3) psychology, (4) susceptibility to outcomes that would be benign in younger, healthier individuals, as well as (5) the worsening of blood glucose regulation into middle age and beyond previously established, amongst (6) other divergent characteristics between adults and middle-aged or older people, we regard a study into effects (beneficial or detrimental) of IF on older subjects to be very important.

One of the experiments in which short-term IF was not beneficial was the pyruvate conversion assay on old Ames Dwarf males or their littermate controls. This stasis is surprising considering (1) the salutary effect seen on middle-aged GHR-KO females and their littermates after short-term IF, (2) the effects seen with other blood glucose-regulatory tests for these Ames Df Stock males, and (3) the fact that the intermittently fasted 


\section{e}

Oldest-Old Ames Dwarf on I.F.

Insulin (0.3) Tolerance Test

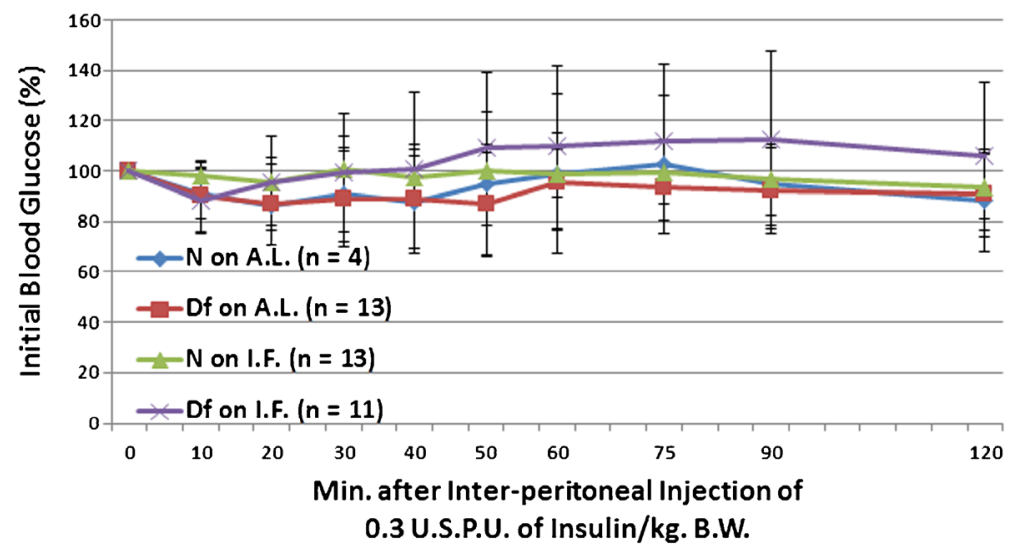

f Oldest-Old Ames Dwarf on I.F. Insulin (0.1) Tolerance Test

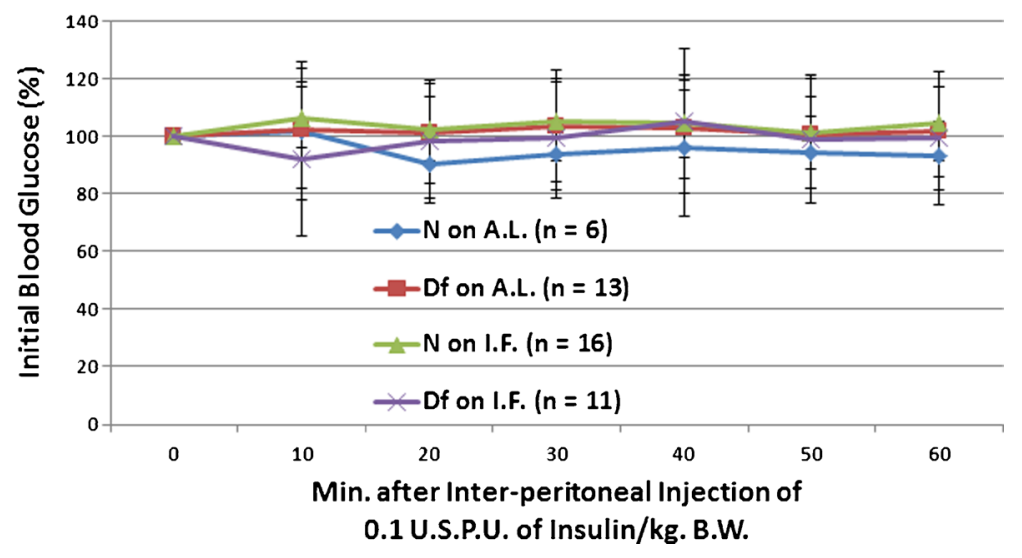

Fig. 6 (continued)

animal subjects underwent periods of fasting that (a priori) might be thought to induce gluconeogenesis, and thus "sharpen" the system for modulating such. While it remains possible that this is a stock-specific effect, it is just as probable that the effect seen on the GHR-KO mice in this test was the stock-specific effect. It is worth noting that these two mutants also diverge in their responses to daily CR in survivorship analyses (Bartke et al. 2001; Bonkowski et al. 2006), and that further survivorship experiments in another $\mathrm{GH}$ signaling-deficient mutant (the GH releasing hormone [GHRH] knockout mouse; Alba and Salvatori 2004) have clarified that dichotomy (Arum, Salvatori, \& Bartke, unpublished data). Therefore, further endocrinological analyses in other senescing GH signaling-deficient mutants might resolve this ambiguity as well.

The surprising detrimental effect of longer-term IF on the glucose clearance of oldest-old Ames Dwarf males merits discussion. It appears that the individual effects and the interaction of (at least) phenotype and diet combine to result in abnormally poor blood glucose assimilation; whether this is in fact a three-factor interaction between age, phenotype, and dietary regimen cannot be discriminated by our experimental design, as we cannot determine whether this observation is simply an effect of the IF diet on extremely old mice or most complexly the effect of an IF diet of that length 


\section{g \\ Old GHR-KO on I.F. Pyruvate Conversion Test}

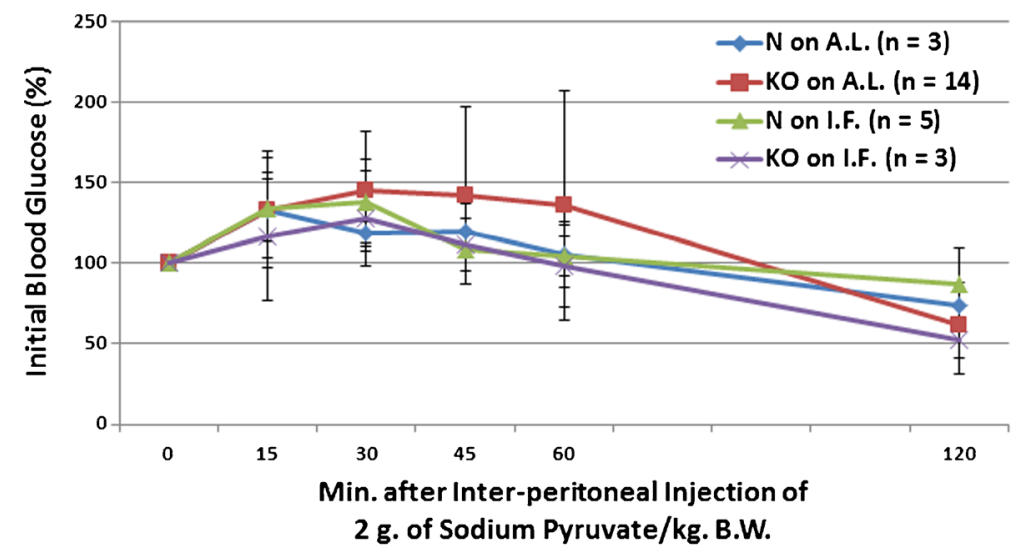

h Oldest-Old Ames Dwarf on I.F. Pyruvate Conversion Test

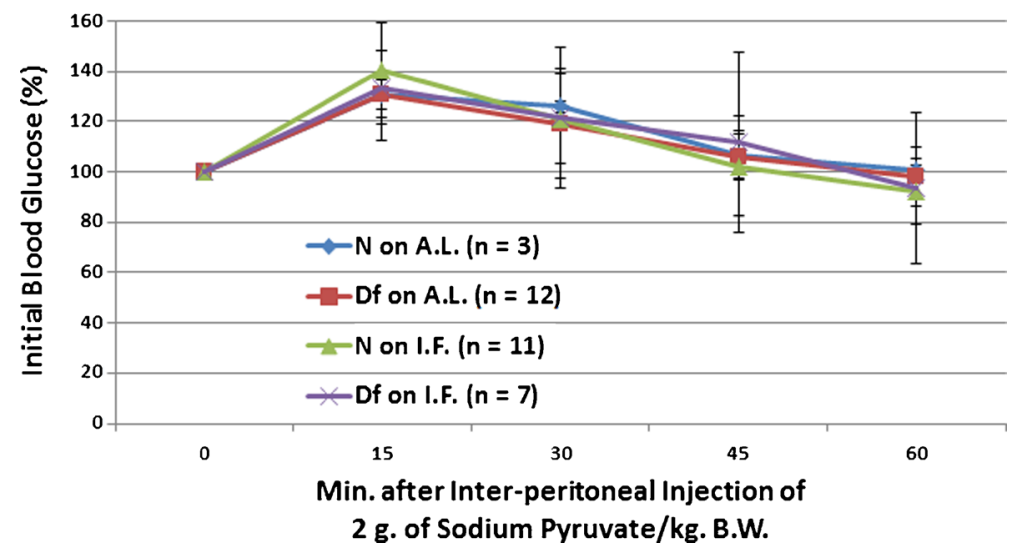

Fig. 6 (continued)

( $\geq 46$ weeks) on extremely elderly mice. The multiple, robustly beneficial results obtained with the longer-term IF diet on old GHR-KO females suggests the former. It is possible that, in extremely elderly animals more susceptible to the wasting of manifold organ systems (e.g., sarcopenia, osteopenia, alopenia), IF is sufficient to push innately hypoinsulinemic animals into insulinopenia; thus resulting in an inability to produce and/or release a sufficient amount of insulin in response to a glucose or insulin challenge.

Moreover, long-term reduced-daily-feeding CR worsened blood glucose tolerance in $\sim 40 \%$ of extremely lean and metabolically healthy subjects; this worsening was associated with declines in IGF-1, total testosterone, leptin, and triiodothyronine concentrations (Fontana et al. 2010). In light of our unexpected findings of worsened glucose tolerance and insulin sensitivity in oldest-old Df males, such prima facie "detrimental" outcomes may actually reflect a protective mechanism against hypoglycemia.

A methodologically important surprising result of this study came from the insulin tolerance tests (ITTs) on middle-aged (Fig. 2c) and old (Fig. 5c) GHR-KO Stock mice employing the $1 \mathrm{USPU} / \mathrm{kg}$ body weight bolus of insulin testing paradigm. At this high concentration, the otherwise-substantial inter-group differences (effect sizes) in insulin responsiveness were sufficiently obscured by high variation that the $p$ value 


\section{a}

Old GHR-KO on I.F.

A.L.-fed Blood Glucose

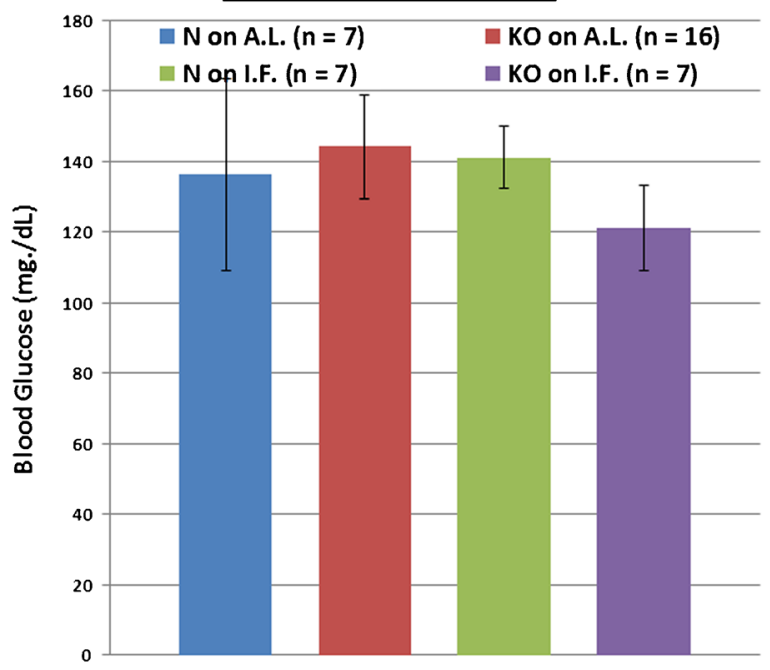

b

Oldest-Old Ames Dwarf on I.F.

A.L.-fed Blood Glucose

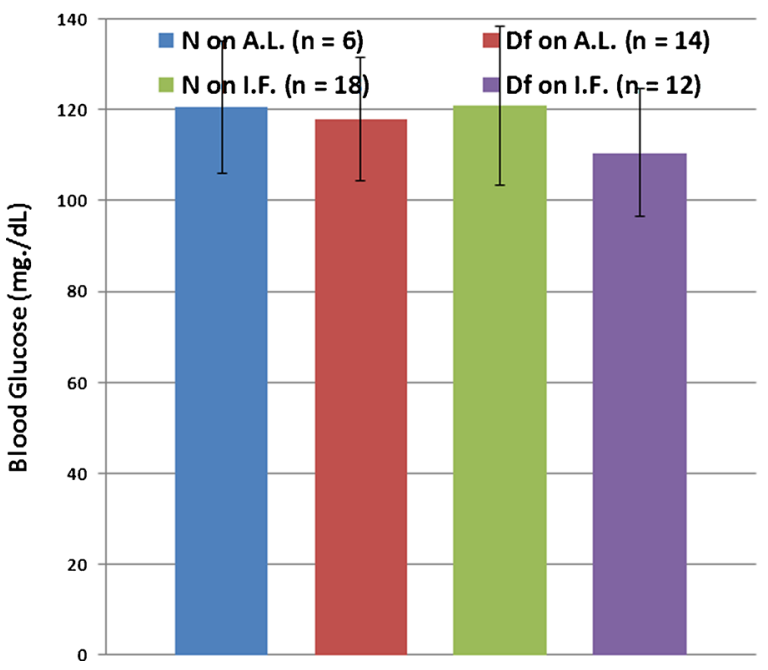

Fig. 7 Differential effects of phenotype or diet on AL-fed or fasted blood glucose concentrations at old (for GHR-KO mice) or oldestold (for Ames Dwarfs) age range. a AL-fed testing of old GHR-KO female mice after longer-term IF (with statistical analysis table) showing blood glucose-lowering effect of a combination of $\mathrm{KO}$ phenotype and IF diet for old KO littermate control females. b Fasted assessment of old GHR-KO females after longer-term IF (with statistical analysis table) exhibiting no blood-glucose lowering effect of either $\mathrm{KO}$ phenotype, IF diet, or combination of $\mathrm{KO}$

for the primary comparisons of $\mathrm{N}$ mice on $\mathrm{AL}$ vs. $\mathrm{KO}$ mice on AL did not reach comfortably low levels; regardless of the subjects' age at testing. Conversely,
C

Old GHR-KO on I.F. Fasted Blood Glucose

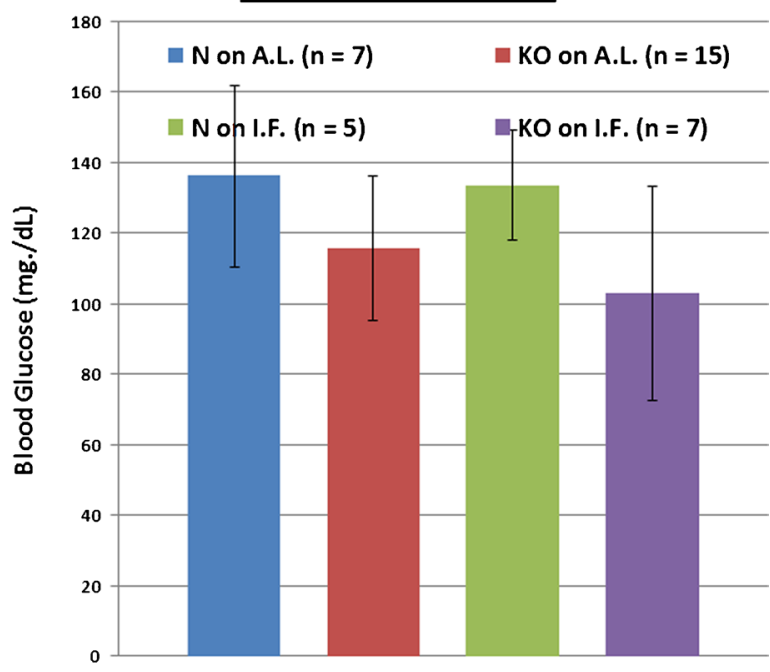

d

Oldest-Old Ames Dwarf on I.F. Fasted Blood Glucose

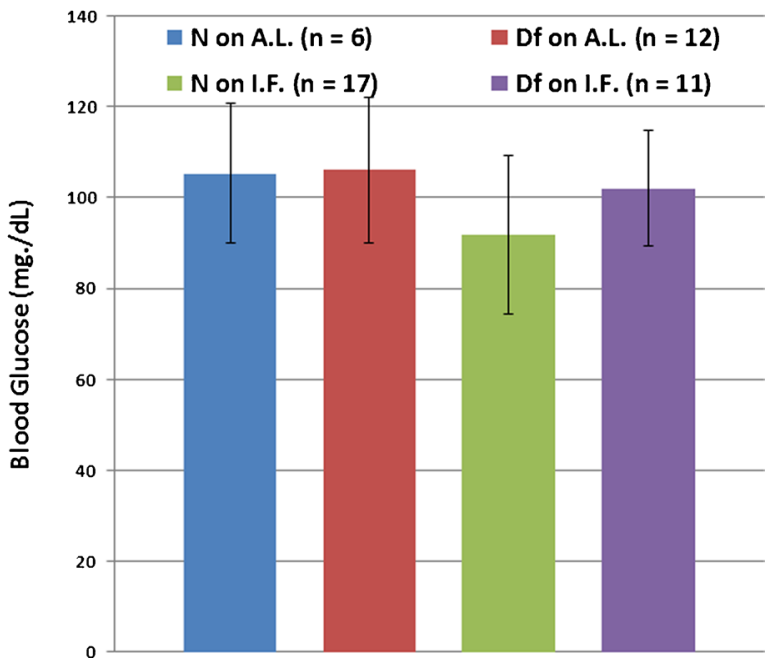

phenotype and IF diet. c AL-fed testing of oldest-old Ames Dwarf male mice after longer-term IF (with statistical analysis table) displaying no blood glucose-lowering effect of either Df phenotype, IF diet, or combination of the two factors. $\mathbf{d}$ Fasted assessment of oldest-old Ames Dwarf male mice after longer-term IF (with statistical analysis table) demonstrating no blood glucose-lowering effect of either Df phenotype, IF diet, or combination of the two. All measures of central tendency are arithmetic means, and all depictions of variation (error bars) represent standard deviations $(S D)$

this issue did not manifest in ITT's using $0.3 \mathrm{USPU} / \mathrm{kg}$ BW (Fig. 5d) or 0.1 USPU/kg BW (Fig. 5e) of insulin. In addition to this seemingly detrimental effect of 
applying a greater-than-necessary dosage in a regimen, it is worth considering that endogenous basal circulating insulin levels are $\sim 10 \mu \mathrm{IU} / \mathrm{ml}$; therefore, it does not come as a surprise that the more discrete tests of "sensitivity" reveal inter-group differences that the coarser method could not.

It is worth noting that, although hypoinsulinemia and enhanced insulin sensitivity have been extensively linked with life extension in GH-related mutants and in CR animals, a few putatively long-lived mutants have been reported as not being so (Conover and Bale 2007; Conover et al. 2008) or as being insulin-resistant (Kurosu et al. 2005; Bartke 2006). An alternative hypothesis regarding the non-cell-autonomous importance of insulin action for health and survivorship posits that insulin resistance may be viewed in certain circumstances as a protective, or even beneficial, adaptation to aging- or diet-related increases in insulin levels (Barzilai et al. 2012). Thusly, our interpretation of decreasing insulin sensitivity in older or elderly subjects is that of a "desensitizing" effect, not a necessarily pernicious effect.

The concept of the "Longevity Dividend" (that faster, more efficient, less expensive gains in gerontological research, and ultimate geriatric care, can be achieved by studying long-lived non-human animals) is substantiated by reports detailing that animals that live longer than their controls have been repeatedly documented to retain multiple features of their health beyond simple survivorship (Olshansky et al. 2007; Warner and Sierra 2009; Miller 2009; Kenyon 2010). Thusly, we designed this investigation of the endocrinological benefits of two genetic alterations and one diet that have each independently had their abilities to increase life expectancy (under varying methodological conditions) published multiple times.

As with the seminal IF study to document longevity (Carlson and Hoelzel 1946), this study was explicitly designed with IF as the low-cost, low-effort intervention of choice due primarily to the potential translatability of any beneficial results obtained. IF has been shown to be reasonably applicable to human subjects (Heilbronn et al. 2005; Klempel et al. 2010; Trepanowski and Bloomer 2010; Trepanowski et al. 2011). Both normal (Heilbronn et al. 2005) and obese (Varady et al. 2009) human subjects have shown suitable compliance with clinical research protocols involving IF. Yet compliance to IF in middle-aged or senior populations has not, to date, been investigated; even though many seniors fail to adhere to dietary and/or lifestyle routines that maintain a salubrious body weight (Johnson 2013). It is not unreasonable to prognosticate that a diet that does not alter the dietary (macronutrient or micronutrient) composition of foods consumed, does not greatly alter the amount of calories consumed, and that permits postfasting gorging, would be more appealing to most patients than one(s) enforcing a drastic, continuous reduction in daily caloric intake.

\section{Materials and methodologies}

Animal husbandry

All animals were bred in a closed colony, housed under standard conditions (12-h light/dark cycle and $20-23^{\circ} \mathrm{C}$ temperature), and fed Lab Diet Formula 5001 (23\% protein, $4.5 \%$ fat, and $6 \%$ fiber) (Nestle-Purina, St. Louis, MO, USA). ME is empirically defined as the amount of gross energy available to the animal once the energy from feces, urine, and combustible gasses are removed. Basically, ME is the energy left for the animal to use once all digestion is complete, and is calculated as $3.02 \mathrm{kcal} / \mathrm{g}$ of Lab Diet Formula 5001 based on manufacturer's instructions (Nestle-Purina). Animal protocols were approved by the Animal Care and Use Committee of Southern Illinois University.

GHR-KO mice and their heterozygous littermate controls, provided by Dr. J.J. Kopchick (Ohio University, Athens, OH, USA), were derived from 129/Ola founders and outbred to Balb/c, C57Bl/6 J, and $\mathrm{C} 3 \mathrm{HJ}$ stocks. Therefore, although lacking the methodological benefits of "reproducible genetic heterogeneity" (Miller et al. 1999), this stock possesses considerably greater genetic variation, which correlates with broad-based health and life expectancy, than an inbred strain.

Ames Dwarf mice and their heterozygous littermate controls have, to the best of our knowledge, a unique genetic background, with respect to extant inbred strains of mice; and this stock exhibits approximately $25 \%$ polymorphism at examined loci (Panici et al. 2009). Thus, although without the methodological benefits of "reproducible genetic heterogeneity" (Miller et al. 1999), this stock possesses considerably more genetic variation, which correlates with broad-based health and life expectancy, than an inbred strain.

Somatotrophic signaling-deficient mice have such a marked difference in snout-to-anus length, being approximately $80 \%$ of the length of their littermates, that 
these animals are grouped by their "dwarf" phenotype. They are not genotyped, as prior genotypingcorroborated experience has proven that it is redundant and unnecessary (Gage et al. 1996). (Note well that this method of classification obviates the potential confound of using weight as the distinguishing characteristic, as that can be complicated in certain instances because the Ames Dwarfs and the GHR-KO mutants - both of which lack lipolytic GH signaling - have increased subcutaneous adiposity [Berryman et al. 2004, 2010].)

\section{Administration of IF paradigm}

Concerning institution and conduct of the IF dietary restriction regimen, approximately 15 - to 19-monthold GHR-KO Stock female mice and approx. 12- to 16-month-old Ames Dwarf Stock male mice were dietarily restricted by having all of the food removed from their food-hoppers on day $X$, and having $60 \mathrm{~g}$ of food deposited into the food-hoppers on day $X+1$; save for interruptions resulting from provisions made for before or after blood glucose regulatory assessments, this feeding pattern continued until the conclusion of the study (approximately 70 weeks after inception of IF).

Age-grade classification

Age-staging was based on a combination of (1) quantitative extrapolation from prior survivorship data (Brown-Borg et al. 1996), Bonkowski et al. 2006), specific to each stock; (2) presence/appearance of aging-associated wizening (as represented quantitatively by declining body weight); and (3) spontaneous, testing-independent (and thus, presumably) agingresultant mortality.

Expounding on the chief age-staging criterion above: young adulthood is marked by at least $90 \%$ of reproductively competent negative control subjects being alive; middle age is the period between when approximately $90 \%$ of the control subjects are still alive and median survivorship; old age is the period between median survivorship and when approx. $10 \%$ of the subjects are alive; and oldestold age is designated as the period when $\leq 10 \%$ of the controls remain.

The second and third criteria add observational corroboration and protection to the first, so that demographic expectations are ensured to coincide with animal husbandry observations.
N.b.: Male littermates of the Ames Dwarf Stock were already into the weight-loss phase of their body weight trajectory before the institution of the IF regimen upon them (at which time they were considered to be old) and subsequent testing of the effects of short-term IF upon them (Fig. 1b); they had further progressed to a greater weight-loss rate by the time that they were regarded as oldest-old, and tested as such (Fig. 1b). Contrastingly, littermate control females of the GHR-KO Stock exhibited stable body weight at the time of IF commencement (at which time they were staged as middle-aged) and successive testing of the effects of short-term IF upon them (Fig. 1a); they then advanced to the weight-loss phase by the time that they were regarded as old, and tested as such (Fig. 1a).

\section{Blood glucose regulatory assessments}

All animals underwent home-cage assessments of gross health (Table S1). Any animal exhibiting questionable health by these criteria, or which was aberrantly hypoglycemic at the inception of a test, was excluded from the testing and/or data analysis. Also, all animals were given at least 2 weeks of recuperation in between tests.

\section{Glucose tolerance tests (AL-fed or fasted)}

For AL-fed tests, animals had access to food for at least $16 \mathrm{~h}$ before the test. For fasted tests, animals were fasted for approximately $16 \mathrm{~h}$; IF animals were AL-fed the day before the 16-h fast commenced. Thirty minutes prior to the beginning of the test, each animal was weighed, had a small nick placed at the tip of its tail with a razor, and rehoused without access to food. After $30 \mathrm{~min}$ to recover from the handling stress of the weighing and tail-nicking, each animal was measured for blood glucose concentration, of blood obtained by applying gentle pressure to the tail tip, with a blood glucose monitoring system (glucometer and test strips) (WaveSense Presto, AgaMatrix, Inc., Salem, NH, USA); without releasing the animal, it was also injected interperitoneally (in the lumen between the visceral and parietal peritonea) with $2 \mathrm{~g}$ of D-(+)-glucose (Sigma-Aldrich, St. Louis, MO, USA) per $\mathrm{kg}$ of BW. (The powdered glucose was dissolved in $0.9 \%$ sodium chloride.) Subsequent blood glucose measurements were at 10, 20, 30, 40, 50, 60, 75, 90 , and $120 \mathrm{~min}$ after the injection. Animals were given AL access to food immediately after completion of testing. 


\section{Insulin tolerance tests $(1,0.3$, or 0.1 USPU)}

Animals had access to food for at least $16 \mathrm{~h}$ before the test. Thirty minutes prior to the beginning of the test, each animal was weighed, had a small nick placed at the tip of its tail with a razor, and re-housed without access to food. After $30 \mathrm{~min}$ to recover from the handling stress of the weighing and tail-nicking, each animal was measured for blood glucose concentration, of blood obtained by applying gentle pressure to the tail tip, with a blood glucose monitoring system (glucometer and test strips) (WaveSense Presto); without releasing the animal, it was also injected interperitoneally (in the space between the visceral and parietal peritonea) with either $1,0.3$, or 0.1 USPU of porcine insulin (Sigma-Aldrich) per kilogram of body weight. (The lyophilized insulin was dissolved in $0.9 \%$ sodium chloride.) Subsequent blood glucose measurements were at 10,20,30, 40, 50,60, 75, 90 , and $120 \mathrm{~min}$ after the injection; unless most animals had returned to initial blood glucose values by $60 \mathrm{~min}$, in which case the test may have been terminated after the 60-min measurement. Animals were given AL access to food immediately after completion of testing.

\section{Pyruvate conversion test}

Animals were fasted for $16 \mathrm{~h}$, although IF animals were AL-fed the day before the fast commenced. Thirty minutes prior to the beginning of the test, each animal was weighed, had a small nick placed at the tip of its tail with a razor, and re-housed without access to food. After 30 min to recover from the handling stress of the weighing and tail-nicking, each animal was measured for blood glucose concentration, of blood obtained by applying gentle pressure to the tail tip, with a blood glucose monitoring system (glucometer and test strips) (WaveSense Presto); without releasing the animal, it was also injected inter-peritoneally (in the cavity between the visceral and parietal peritonea) with $2 \mathrm{~g}$ of sodium pyruvic acid (Sigma-Aldrich) per kg of BW. (The lyophilized sodium pyruvate was dissolved in $0.9 \%$ sodium chloride.) Subsequent blood glucose measurements were at 15, 30, 45, 60, and 120 min after the injection; unless most animals had returned to initial blood glucose values by $60 \mathrm{~min}$, in which case the test may have been terminated after the 60-min measurement. Animals were given AL access to food immediately after completion of testing.
Non-stimulated blood glucose comparisons (AL-fed or fasted)

Values recorded at the beginnings of AL-fed and fasted glucose tolerance tests were used for this analysis. The reasoning for this was twofold: (1) as the glucose tolerance tests occur early in the series of tests that the animals subjects were subjected to within each testing period, the likelihood of potentially confounding effects from earlier tests is minimized; and (2) also as the glucose tolerance tests occur early in the series of tests for each testing interval, the simple-yet-potentially-profound effects of advancing age are also minimized. (Note that unstimulated blood glucose values obtained at other instances were consistent with the reported results.)

Data presentation and statistical analysis

Graphs were generated with Excel (Microsoft, Redmond, WA, USA). All measures of central tendency are arithmetic means, and all depictions of variation (error bars) represent standard deviations (SD); with SD being employed as it is the statistically appropriate method of representing the variation in a dataset (Glantz 2002).

Body weight-gain data, food and energy consumption data, and blood glucose regulatory assessment data was contrasted with analysis of variance (ANOVA) or ANOVA for repeated measures (ANOVA-RM), as appropriate, followed by the Tukey's honestly significant difference (HSD) post-hoc test for multiple pairwise comparisons (SPSS 17.0, SPSS Inc., Chicago, IL, USA).

For repeatedly measured blood glucose regulatory assessments, the $p$ value for a given pairwise comparison at a given time-point represents the result of testing all of the timepoints, up-to-and-including that timepoint, within the repeated measures analysis; this permits testing of whether both groups experienced similar excursions in blood glucose (the null hypothesis) relative to their initial values and with consideration of all intermediate values. This mode of analysis permits the posing of more discrete, and more descriptive, queries than analyses of the entire area under respective curves; or that utilizing isolated, independent blood glucose values/percentages at lone timepoints. The data that is normalized to initial blood glucose values was used for the precise, timepoint-specific $p$ values reported, yet the conclusions of differences amongst groups do not 
depend on the use of this normalized data; testing plots of raw data are presented in Supplementary figures.

For a particular pairwise comparison within a particular assay, the $p$ value reported in the text is either the most-conservative (i.e., highest) sub-0.05 $p$ value from the series of ANOVA-RM's conducted (in bold, red font), or the lowest tentative $p$ value from the series (in bold, orange font); the tentative $p$ values noted in the text are supported by a priori evidence. The combined parameters of effect size and Type 1 error probability were considered when determining phenomena meriting presentation and discussion.

Acknowledgments This work was supported by National Institute on Aging Grants AG19899, U19 AG023122, and 3R01AG01989907S1, as well as a Senior Scholar Award in Aging from The Ellison Medical Foundation and The Glenn Foundation for Medical Research; this work was vitally supported by a grant from the Center for Alzheimer's Disease and Related Disorders at The Southern Illinois University, and the authors especially thank Drs. Thomas A. Ala and Robert G. Struble.

Conflict of interest The authors aver that they have no conflicts of interest related to this publication.

Authors' contributions O.A. and A.B.. acquired funding for this study; O.A. conceived and designed this study; O.A. and R.K.B. methodologically executed this study; O.A. statistically analyzed the data; O.A., J.K.S., R.K.K., and A.B.. prepared the manuscript for this study; and J.J.K. provided founder populations of some of the mice used for this study.

\section{References}

Alba M, Salvatori R (2004) A mouse with targeted ablation of the growth hormone-releasing hormone gene: a new model of isolated growth hormone deficiency. Endocrinology 145(9): 4134-4143

Alengrin F, Grossi G, Canivet B, Dolais-Kitabgi J (1987) Inhibitory effects of metformin on insulin and glucagon action in rat hepatocytes involve post-receptor alterations. Diabete Metab 13(6):591-597

Anson RM, Guo Z, de Cabo R, Iyun T, Rios M, Hagepanos A, Ingram DK, Lane MA, Mattson MP (2003) Intermittent fasting dissociates beneficial effects of dietary restriction on glucose metabolism and neuronal resistance to injury from calorie intake. Proc Natl Acad Sci U S A 100(10):6216-6220

Anson RM, Jones B, de Cabo R (2005) The diet restriction paradigm: a brief review of the effects of every-other-day feeding. Age 27:7-25

Arum O, Bonkowski MS, Rocha JS, Bartke A (2009) The growth hormone receptor gene-disrupted mouse fails to respond to an intermittent fasting diet. Aging Cell 8(6):756-760
Arum O, Rasche ZA, Rickman DJ, Bartke A. (2013) Prevention of neuromusculoskeletal frailty in slow-aging ames dwarf mice: longitudinal investigation of interaction of longevity genes and caloric restriction. PLoS One 8(10):e72255. doi:10.1371/ journal.pone.0072255

Arum O, Rickman DJ, Kopchick JJ, Bartke A (2014) The slowaging growth hormone receptor/binding protein genedisrupted (GHR-KO) mouse is protected from aging-resultant neuromusculoskeletal frailty. Age (Dordr) 36(1):117-27. doi:10.1007/s11357-013-9551-x

Bartke A (1965) The response of two types of dwarf mice to growth hormone, thyrotropin, and thyroxine. Gen Comp Endocrinol 5:418-426

Bartke A (2006) Long-lived Klotho mice: new insights into the roles of IGF-1 and insulin in aging. Trends Endocrinol Metab 17(2):33-35

Bartke A (2008) Insulin and aging. Cell Cycle 7(21):3338-3343

Bartke A (2011) Single-gene mutations and healthy ageing in mammals. Philos Trans R Soc Lond B Biol Sci 366(1561): 28-34

Bartke A (2012) Healthy aging: is smaller better? — a minireview. Gerontology 58:337-343

Bartke A, Brown-Borg H (2004) Life extension in the dwarf mouse. Curr Top Dev Biol 63:189-225

Bartke A, Wright JC, Mattison JA, Ingram DK, Miller RA, Roth GS (2001) Extending the lifespan of long-lived mice. Nature 414(6862):412

Barzilai N, Huffman DM, Muzumdar RH, Bartke A (2012) The critical role of metabolic pathways in aging. Diabetes 61(6): $1315-1322$

Berryman DE, List EO, Coschigano KT, Behar K, Kim JK, Kopchick JJ (2004) Comparing adiposity profiles in three mouse models with altered GH signaling. Growth Hormon IGF Res 14(4):309-318

Berryman DE, Christiansen JS, Johannsson G, Thorner MO, Kopchick JJ (2008) Role of the GH/IGF-1 axis in lifespan and healthspan: lessons from animal models. Growth Hormon IGF Res 18(6):455-471

Berryman DE, List EO, Palmer AJ, Chung MY, Wright-Piekarski J, Lubbers E, O'Connor P, Okada S, Kopchick JJ (2010) Twoyear body composition analyses of long-lived GHR null mice. J Gerontol A Biol Sci Med Sci 65(1):31-40

Bonkowski MS, Rocha JS, Masternak MM, Al Regaiey KA, Bartke A (2006) Targeted disruption of growth hormone receptor interferes with the beneficial actions of calorie restriction. Proc Natl Acad Sci U S A 103(20):7901-7905

Boparai RK, Arum O, Khardori R, Bartke A (2010) Glucose homeostasis and insulin sensitivity in growth hormonetransgenic mice: a cross-sectional analysis. Biol Chem 391(10):1149-1155

Borg KE, Brown-Borg HM, Bartke A (1995) Assessment of the primary adrenal cortical and pancreatic hormone basal levels in relation to plasma glucose and age in the unstressed Ames dwarf mouse. Proc Soc Exp Biol Med 210(2):126-133

Bourdel-Marchasson I, Berrut G (2005) Caring the elderly diabetic patient with respect to concepts of successful aging and frailty. Diabetes Metab 31(2):5S13-5S19

Brown-Borg HM, Borg KE, Meliska CJ, Bartke A (1996) Dwarf mice and the ageing process. Nature 384(6604):33

Carlson AJ, Hoelzel F (1946) Apparent prolongation of the life span of rats by intermittent fasting. J Nutr 31:363-375 
Centers for Disease Control and Prevention. Atlanta, GA: Centers for Disease Control and Prevention, US Department of Health and Human Services (2011) National Diabetes Fact Sheet, 2011. (http://www.cdc.gov/diabetes/pubs/pdf/ndfs_2011.pdf)

Centers for Disease Control and Prevention. Atlanta, GA: Centers for Disease Control and Prevention, US Department of Health and Human Services (2012) Diabetes Report Card 2012. (http://www.cdc.gov/ diabetes/pubs/pdf/DiabetesReportCard.pdf)

Chang AM, Halter JB (2003) Aging and insulin secretion. Am J Physiol Endocrinol Metab 284(1):E7-E12

Chen LK, Chen YM, Lin MH, Peng LN, Hwang SJ (2010) Care of elderly patients with diabetes mellitus: a focus on frailty. Ageing Res Rev 9(Suppl 1):S18-S22

Collier B, Dossett LA, May AK, Diaz JJ (2008) Glucose control and the inflammatory response. Nutr Clin Pract 23(1):3-15

Conover CA, Bale LK (2007) Loss of pregnancy-associated plasma protein A extends lifespan in mice. Aging Cell 6(5):727-729

Conover CA, Mason MA, Levine JA, Novak CM (2008) Metabolic consequences of pregnancy-associated plasma protein-A deficiency in mice: exploring possible relationship to the longevity phenotype. J Endocrinol 198(3):599-605

Coschigano KT et al. (1999) 81st Annual Meeting of the Endocrine Society, San Diego, CA

Coschigano KT, Clemmons D, Bellush LL, Kopchick JJ (2000) Assessment of growth parameters and life span of GHR/BP gene-disrupted mice. Endocrinology 141(7):2608-2613

Coschigano KT, Holland AN, Riders ME, List EO, Flyvbjerg A, Kopchick JJ (2003) Deletion, but not antagonism, of the mouse growth hormone receptor results in severely decreased body weights, insulin, and insulin-like growth factor I levels and increased life span. Endocrinology 144(9):3799-3810

Couet C, Delarue J, Constans T, Lamisse F (1992) Age-related insulin resistance: a review. Horm Res 38(1-2):46-50

Cozzi R, Attanasio R (2012) Octreotide long-acting repeatable for acromegaly. Expert Rev Clin Pharmacol 5(2):125-143

Crandall JP, Shamoon H, Cohen HW, Reid M, Gajavelli S, Trandafirescu G, Tabatabaie V, Barzilai N (2009) Postchallenge hyperglycemia in older adults is associated with increased cardiovascular risk profile. J Clin Endocrinol Metab 94(5):1595-1601

Dominguez LJ, Paolisso G, Barbagallo M (2010) Glucose control in the older patient: from intensive to effective and safe. Aging Clin Exp Res 22(4):274-280

Dominici FP, Hauck S, Argentino DP, Bartke A, Turyn D (2002) Increased insulin sensitivity and upregulation of insulin receptor, insulin receptor substrate (IRS)-1 and IRS-2 in liver of Ames dwarf mice. J Endocrinol 173(1):81-94

Farrokhi F, Smiley D, Umpierrez GE (2011) Glycemic control in non-diabetic critically ill patients. Best Pract Res Clin Endocrinol Metab 25(5):813-824

Finch CE (2009) The neurobiology of middle-age has arrived. Neurobiol Aging 30(4):515-520, discussion 530-33

Flurkey K, Papaconstantinou J, Miller RA, Harrison DE (2001) Lifespan extension and delayed immune and collagen aging in mutant mice with defects in growth hormone production. Proc Natl Acad Sci U S A 98(12):6736-6741

Fontana L, Meyer TE, Klein S, Holloszy JO (2004) Long-term calorie restriction is highly effective in reducing the risk for atherosclerosis in humans. Proc Natl Acad Sci U S A 101(17):6659-6663
Fontana L, Klein S, Holloszy JO (2010) Effects of long-term calorie restriction and endurance exercise on glucose tolerance insulin action, and adipokine production. Age (Dordr) 32(1):97-108

Gage PJ, Roller ML, Saunders TL, Scarlett LM, Camper SA (1996) Anterior pituitary cells defective in the cellautonomous factor, df, undergo cell lineage specification but not expansion. Development 122(1):151-160

Glantz SA (2002) Primer of biostatistics. How to summarize data (Chapter 2), 5th edn. McGraw-Hill, New York, NY

Gong Z, Muzumdar RH (2012) Pancreatic function type 2 diabetes, and metabolism in aging. Int J Endocrinol 2012:320482

Goto S (2006) Health span extension by later-life caloric or dietary restriction: a view based on rodent studies. Biogerontology $7(3): 135-138$

Greene DA (1986) Acute and chronic complications of diabetes mellitus in older patients. Am J Med 80(5A):39-53

Guo Y, Lu Y, Houle D, Robertson K, Tang Z, Kopchick JJ, Liu YL, Liu JL (2005) Pancreatic islet-specific expression of an insulin-like growth factor-I transgene compensates islet cell growth in growth hormone receptor gene-deficient mice. Endocrinology 146(6):2602-2609

Halter JB (2012) Diabetes mellitus in an aging population: the challenge ahead. J Gerontol A Biol Sci Med Sci 67(12): 1297-1299

Heilbronn LK, Smith SR, Martin CK, Anton SD, Ravussin E (2005) Alternate-day fasting in nonobese subjects: effects on body weight, body composition, and energy metabolism. Am J Clin Nutr 81(1):69-73

Heilbronn LK, de Jonge L, Frisard MI, DeLany JP, Larson-Meyer DE, Rood J, Nguyen T, Martin CK, Volaufova J, Most MM, Greenway FL, Smith SR, Deutsch WA, Williamson DA, Ravussin E, Pennington CALERIE Team (2006) Effect of 6-month calorie restriction on biomarkers of longevity, metabolic adaptation, and oxidative stress in overweight individuals: a randomized controlled trial. JAMA 295(13):15391548, Erratum in: JAMA. 2006 Jun 7;295(21):2482

Hundal RS, Krssak M, Dufour S, Laurent D, Lebon V, Chandramouli V, Inzucchi SE, Schumann WC, Petersen KF, Landau BR, Shulman GI (2000) Mechanism by which metformin reduces glucose production in type 2 diabetes. Diabetes 49(12):2063-2069

Ikeno Y, Bronson RT, Hubbard GB, Lee S, Bartke A (2003) Delayed occurrence of fatal neoplastic diseases in Ames dwarf mice: correlation to extended longevity. J Gerontol A Biol Sci Med Sci 58(4):291-296

Ikeno Y, Hubbard GB, Lee S, Cortez LA, Lew CM, Webb CR, Berryman DE, List EO, Kopchick JJ, Bartke A (2009) Reduced incidence and delayed occurrence of fatal neoplastic diseases in growth hormone receptor/binding protein knockout mice. J Gerontol A Biol Sci Med Sci 64(5):522-529

Johnson MA (2013) Strategies to improve diet in older adults. Proc Nutr Soc 72(1):166-172

Kenyon CJ (2010) The genetics of ageing. Nature 464(7288):504 512, Erratum in: Nature. 2010 Sep 30;467(7315):622

Kinney BA, Coschigano KT, Kopchick JJ, Steger RW, Bartke A (2001a) Evidence that age-induced decline in memory retention is delayed in growth hormone resistant GH-R-KO (Laron) mice. Physiol Behav 72(5):653-660

Kinney BA, Meliska CJ, Steger RW, Bartke A (2001b) Evidence that Ames dwarf mice age differently from their normal 
siblings in behavioral and learning and memory parameters. Horm Behav 39(4):277-284

Kinney-Forshee BA, Kinney NE, Steger RW, Bartke A (2004) Could a deficiency in growth hormone signaling be beneficial to the aging brain? Physiol Behav 80(5):589-594

Kinsella K, Wan H (2009) U.S. Census Bureau, International Population Reports, P95/09-1, An aging world: 2008. U.S. Government Printing Office, Washington, DC. (http://www. census.gov/prod/2009pubs/p95-09-1.pdf)

Klempel MC, Bhutani S, Fitzgibbon M, Freels S, Varady KA (2010) Dietary and physical activity adaptations to alternate day modified fasting: implications for optimal weight loss. Nutr J 9:35

Klover PJ, Mooney RA (2004) Hepatocytes: critical for glucose homeostasis. Int J Biochem Cell Biol 36(5):753-758

Kurosu H, Yamamoto M, Clark JD, Pastor JV, Nandi A, Gurnani P, McGuinness OP, Chikuda H, Yamaguchi M, Kawaguchi H, Shimomura I, Takayama Y, Herz J, Kahn CR, Rosenblatt KP, Kuro-o M (2005) Suppression of aging in mice by the hormone Klotho. Science 309(5742):1829-1833

Lazar HL (2012) How important is glycemic control during coronary artery bypass? Adv Surg 46:219-235

Liu JL, Coschigano KT, Robertson K, Lipsett M, Guo Y, Kopchick JJ, Kumar U, Liu YL (2004) Disruption of growth hormone receptor gene causes diminished pancreatic islet size and increased insulin sensitivity in mice. Am J Physiol Endocrinol Metab 287(3):E405-E413

Lu J, Lezi E, Wang W, Frontera J, Zhu H, Wang WT, Lee P, Choi IY, Brooks WM, Burns JM, Aires D, Swerdlow RH (2011) Alternate day fasting impacts the brain insulin-signaling pathway of young adult male C57BL/6 mice. J Neurochem 117(1):154-163

Mair W, Goymer P, Pletcher SD, Partridge L (2003) Demography of dietary restriction and death in Drosophila. Science 301(5640):1731-1733

Martin B, Mattson MP, Maudsley S (2006) Caloric restriction and intermittent fasting: two potential diets for successful brain aging. Ageing Res Rev 5(3):332-353

Mattson MP, Duan W, Guo Z (2003) Meal size and frequency affect neuronal plasticity and vulnerability to disease: cellular and molecular mechanisms. J Neurochem 84(3):417-431

McCay CM, Crowell MF, Maynard LA (1935) The effect of retarded growth upon the length of life span and upon the ultimate body size. Nutrition 5(3):155-171, discussion 172

Miller RA (2009) "Dividends" from research on aging — can biogerontologists, at long last, find something useful to do? J Gerontol A Biol Sci Med Sci 64(2):157-160

Miller RA, Burke D, Nadon N (1999) Announcement: four-way cross mouse stocks: a new, genetically heterogeneous resource for aging research. J Gerontol A Biol Sci Med Sci 54(8):B358-B360

Moghissi ES (2010) Reexamining the evidence for inpatient glucose control: new recommendations for glycemic targets. Am J Health Syst Pharm 67(16 Suppl 8):S3-S8

Moreschi C (1909) Ztschr. f. Immunitätsforsch. u. exper. Therap 2: 651

Olshansky SJ, Perry D, Miller RA, Butler RN (2007) Pursuing the longevity dividend: scientific goals for an aging world. Ann N Y Acad Sci 1114:11-13

Panici JA, Wang F, Bonkowski MS, Spong A, Bartke A, Pawlikowska L, Kwok PY, Masternak MM (2009) Is altered expression of hepatic insulin-related genes in growth hormone receptor knockout mice due to $\mathrm{GH}$ resistance or a difference in biological life spans? J Gerontol A Biol Sci Med Sci 64(11):1126-1133

Pucher J, Stewart J (2004) Periodontal disease and diabetes mellitus. Curr Diab Rep 4(1):46-50

Rochon J, Bales CW, Ravussin E, Redman LM, Holloszy JO, Racette SB, Roberts SB, Das SK, Romashkan S, Galan KM, Hadley EC, Kraus WE, CALERIE Study Group (2011) Design and conduct of the CALERIE study: comprehensive assessment of the long-term effects of reducing intake of energy. J Gerontol A Biol Sci Med Sci 66(1):97-108

Roe FJC, Lee PN, Conybeare G, Kelly D, Matter B, Prentice D, Tobin G (1995) The BIOSURE Study: influence of composition of diet and food consumption on longevity, degenerative diseases and neoplasia in Wistar rats studied for up to 30 months postweaning. Food Chem Toxicol 33(Suppl 1): 1S-100S

Roth LW, Polotsky AJ (2012) Can we live longer by eating less? A review of caloric restriction and longevity. Maturitas 71(4): 315-319

Rous P (1914) The influence of diet on transplanted and spontaneous mouse tumors. J Exp Med 20(5):433-451

Salonen PH, Koskela HO, Niskanen L (2012) Prevalence and determinants of hyperglycaemia in pneumonia patients. Scand J Infect Dis 45(2):88-94

Schaible R, Gowen JW (1961) A new dwarf mouse. Genetics 46: 896

Slabaugh M, Lieberman M, Rutledge J, Gorski J (1981) Growth hormone and prolactin synthesis in normal and homozygous Snell and Ames dwarf mice. Endocrinology 109:1040-1046

Smith NL, Savage PJ, Heckbert SR, Barzilay JI, Bittner VA, Kuller LH, Psaty BM (2002) Glucose, blood pressure, and lipid control in older people with and without diabetes mellitus: the Cardiovascular Health Study. J Am Geriatr Soc 50(3):416-423

Sornson MW, Wu W, Dasen JS, Flynn SE, Norman DJ, O'Connell SM, Gukovsky I, Carrière C, Ryan AK, Miller AP, Zuo L, Gleiberman AS, Andersen B, Beamer WG, Rosenfeld MG (1996) Pituitary lineage determination by the Prophet of Pit-1 homeodomain factor defective in Ames dwarfism. Nature 384(6607):327-333

Topinková E (2008) Aging, disability and frailty. Ann Nutr Metab 52(Suppl 1):6-11

Trepanowski JF, Bloomer RJ (2010) The impact of religious fasting on human health. Nutr J 9:57

Trepanowski JF, Canale RE, Marshall KE, Kabir MM, Bloomer RJ (2011) Impact of caloric and dietary restriction regimens on markers of health and longevity in humans and animals: a summary of available findings. Nutr J 10:107

Valeri C, Pozzilli P, Leslie D (2004) Glucose control in diabetes. Diabetes Metab Res Rev 20(Suppl 2):S1-S8

van der Lely AJ, Biller BM, Brue T, Buchfelder M, Ghigo E, Gomez R, Hey-Hadavi J, Lundgren F, Rajicic N, Strasburger CJ, Webb SM, Koltowska-Häggström M (2012) Long-term safety of pegvisomant in patients with acromegaly: comprehensive review of 1288 subjects in ACROSTUDY. J Clin Endocrinol Metab 97(5):1589-1597

Varady KA (2011) Intermittent versus daily calorie restriction: which diet regimen is more effective for weight loss? Obes Rev 12(7):e593-e601 
Varady KA, Hellerstein MK (2007) Alternate-day fasting and chronic disease prevention: a review of human and animal trials. Am J Clin Nutr 86(1):7-13

Varady KA, Bhutani S, Church EC, Klempel MC (2009) Shortterm modified alternate-day fasting: a novel dietary strategy for weight loss and cardioprotection in obese adults. Am J Clin Nutr 90(5):1138-1143

Viljoen A, Sinclair AJ (2011) Diabetes and insulin resistance in older people. Med Clin N Am 95(3):615-629, xi-xii

Viollet B, Guigas B, Sanz Garcia N, Leclerc J, Foretz M, Andreelli F (2012) Cellular and molecular mechanisms of metformin: an overview. Clin Sci (Lond) 122(6): 253-270

Wang C, Weindruch R, Fernández JR, Coffey CS, Patel P, Allison DB (2004) Caloric restriction and body weight independently affect longevity in Wistar rats. Int J Obes Relat Metab Disord 28(3):357-362

Warner H, Sierra F (2009) The longevity dividend: why invest in basic aging research? Can J Aging 28(4):391-394, French 395-8

Wijsman CA, Rozing MP, Streefland TC, le Cessie S, Mooijaart SP, Slagboom PE, Westendorp RG, Pijl H, van Heemst D, Leiden Longevity Study Group (2011) Familial longevity is marked by enhanced insulin sensitivity. Aging Cell 10(1): 114-121

Zhou Y, Xu BC, Maheshwari HG, He L, Reed M, Lozykowski M, Okada S, Cataldo L, Coschigamo K, Wagner TE, Baumann G, Kopchick JJ (1997) A mammalian model for Laron syndrome produced by targeted disruption of the mouse growth hormone receptor/binding protein gene (the Laron mouse). Proc Natl Acad Sci U S A 94(24):13215-13220 